\title{
XVII.
}

\section{Das Neuron des Ganglion ciliare und die Centra der Pupillenbewegungen.*)}

Eine experimentelle Studie.

\author{
Von \\ Dr. Alessandro Marina
}

(Triest).

(Mit Tafel XIII.)

Diese Arbeit knüpft sich an die Ergebnisse einer vergleichenden klinischen Studie über die Augenmuskellähmungen, welche ich im Jahre 1895 publicirt habe ${ }^{1}$ ).

In dem letzten Kapitel dieses Buches ist die Frage der Pupillenreaction erörtert und auseinandergesetzt, wie die Sache nach den letzten experimentellen Studien sich gestaltete, und wie unsicher und widersprechend die Resultate der einzelnen Forscher über das Centrum der Pupillenbewegungen waren.

In der That wurde dieses Centrum von Völker und Hensen in den vorderen Theil des Oculomotoriuskerns, von v. Bechterew ins Centralgrau des dritten Ventrikels, von Mendel ins Ganglion habenulae versetzt.

Beim Menschen wurde der W estphal-Edinger'sche - später der Darksch e wits ch'sche Kern als Centrum angegeben; die späteren Untersuchungen von Siemerling und Anderen haben die erstgenannte Zellengruppe als Centrum nicht bestätigt, und Bernheimer, welchem sich vor Kurzem v. Bechterew ( ${ }^{2}$ ) anschloss, hat gezeigt, dass der Darkschewitsch'sche Kern nicht einmal zur Oculomotoriusgruppe gehört und überhaupt mit der Pupillenreaction nichts zu thun hat.

Ein Ueberblick über das Verhalten der Pupillen bei den verschiedenen Krankheiten lehrte uns ferner, dass die Bewegungen der Iris, Tabes, progressive Paralyse und Syphilis ansgenommen, bei der grössten Mehrzahl der Krankheiten, selbst bei vorhandener Lähmung aller den Bulbus bewegenden Muskeln normal sind. Ueber diesen Punkt bemerkte ich:

„So lange man annahm, dass die betreffenden Kerne (Syphincter-

*) Aus dem Italienischen übersetzt. 
Das Neuron des Ganglion ciliare u. die Centra der Pupillenbewegungen. 357

kerne im Oculomotoriuscentrum) von einem verschiedenen Circulationssystem (Carotis) durchströmt werden, hat man diese Erscheinung halbwegs verstanden; da diese Hypothese als falsch demonstrirt wurde, haben wir für dieses Verhalten keine Erklärung."

In der That habe ich mich durch Gefässinjectionen überzeugen können, was d'Astros als Erster nachweisen konnte, dass alle Kerne des Oculomotorius nur von der Art. cerebralis post., also von der Basilaris mit Blut versorgt werden.

Ueber die drei Krankheiten, welche die meisten Fälle von Pupillenstarre erzeugen, äusserte ich mich folgendermaassen:

"Der pathologische Process ist aber bei dieser nosologischen Trias ein ausgedehnter: es handelt sich um eine centrale und periphere Nervenerkrankung, welch' letztere .... gewiss eine sehr grosse Rolle spielt. .... Denken wir an die ,Wichtigkeit, welche eine Erkrankung des Rückenmarks für die Erweiterung, an die Bedeutung, welche das fast nie untersuchte Ganglion ciliare für die Verengerung der Pupille haben, ferner, von welch' hohem Belang der Zustand des Opticus 'für den Reflex sein kann, so werden wir zu dem Schlusse kommen, dass auch ohne Läsion des Oculomotoriuskernes eine Lähmung der Pupillen bei diesen Krankheiten anzunehmen ist. Wenn man weiter bedenkt, dass die Pupillenstarre zu den fruhesten Symptomen der Tabes gehört, dass sie ohne Erkrankung irgend eines Astes des Oculomotorius durch die ganze Krankheit isolirt besteht, wenn wir uns ferner erinnern, wie man vergebens ein Centrum für die Pupillenverengerung im Oculomotoriuscentrum beim Menschen gesucht hat, so ist die Frage berechtigt: Liegt überhaupt beim Menschen im Oculomotoriuskern das Centrum für die Pupillenverengerung? Besonders das Studium der angeborenen Ophthalmoplegien, der Ophthalmoplegia externa der Erwachsenen, und einiger Formen der Bulbärparalyse fordern zu dieser Frage heraus."

Ich fügte weiter hinzu: „Eine Antwort ist aber noch unmöglich. Es liegt nahe, dass ein Centrum in der Vierhügelgegend sich befindet, weil dort der Reflexbogen zwischen Opticus und Oculomotorius sich schliesst, und die hohe Procentzahl der Pupillenlähmungen scheint jene Annahme nicht nur bei den Tumoren ( $6 \mathrm{mal}$ auf 11 Fälle), bei welchen Fernwirkungen und allgemeine, nicht durch die begrenzte locale Störung bedingte Erscheinungen es verständlich machen, sondern auch bei den Hämorrhagien und Erweichungen dieser Region es zum Theil zu bestätigen. Bei einigen Fällen letzterer Art waren jedoch die Oculomotoriuswurzeln mit oder ohne die Oculomotoriusregion lädirt, andere zeigten verschiedene Herde, so dass kein Fall rein war, ja, es bestand einmal bei einem einseitigen Herde eine beiderseitige Pupillenstarre.

Wenn wir also sagen können, dass im Oculomotorius pupillenver- 
engernde Fasern verlaufen, können wir nicht ohne Weiteres annehmen, dass das hauptsächliche Centrum im Oculomotoriuskern liegt, ja, vom klinischen Standpunkt aus scheint dies nicht der Fall zu sein. Das Ciliarganglion muss für das Phänomen eine hohe Bedeutung besitzen."

Noch weiter bemerkte ich Folgendes:

„Die Frequenz der Pupillenstarre bei Tabes spricht sogar für ein extracerebrales oder wenigstens für ein zweites zwischen Oculomotorius und kurzen Ciliarnerven localisirtes Centrum, welchem eine höhere Bedeutung zugemuthet werden muss. Diese Annahme steht mit der Neuronentheorie ganz gut im Einklang. Nach dieser Theorie ist die Tabes eine Affection des Neurons: periphere Faser, Spinalganglion, hintere Wurzel, Hinterstrangfaser; es wird ferner angenommen, dass, um eine Ganglienzelle in ihrer Function zu stören, der protrahirte Mangel peripherer Reizungen genügt. Wenn wir diese Theorie auf unser Feld übertragen, so haben wir bei lichtstarren Pupillen (bei intactem Opticus) eine Affection des Neurons des Ciliarganglions, nämlich: kurze Ciliarnerven, Ganglion, pupillenverengende Fasern im Oculomotoriusstamm und weiter centralwärts in der Vierhügelgegend. Diese Affection sollte dann auch für dieses Neuron, wie bei der Tabes vorzukommen pflegt, von der Peripherie aus anfangen, die Ciliarnerven und das Ganglion zuerst treffen, und da die Pupillenlähmung zu den ersten Augensymptomen zählt, so giebt eben dieses Phänomen das Ganglion als das bedeutendste Centrum für die Pupillenverengerung. Dasselbe gilt für die progressive Paralyse“. .... u. s. w. „Die hohe Procentzahl der Pupillenlähmungen bei diesen drei (Syphilis mitgerechnet) Krankheiten drängt also durchaus nicht zu der Hypothese, dass das wichtigste Centrum für die Pupillenverengerung im Oculomotoriuscentrum liege, im Gegentheil, man ist fast gezwungen, für die mangelhafte Reaction die peripheren Theile (Ciliarganglion, kurze Ciliarnerven) vorwiegend verantwortlich zu machen."

Ferner bemerkte ich: „Ich muss besonders hervorheben, dass bei verschiedenen Neuritiden des Oculomotorius mit oder ohne Polyneuritiden anderer Nerven die Pupillenbewegungen intact sein können, was wieder als eine Stütze zur Annahme angesehen werden kann, dass das hauptsächliche Centrum für die Verengerung der Pupille nicht central, sondern peripheriewärts vom Oculomotoriusstamm sich befindet, also im Ganglion ciliare."

Endlich schloss ich das Kapitel mit folgendem Satze:

"Ich wollte dem Problem näher treten, da die Hauptbedingung zur Lösung einer Frage darin besteht, sie nach allen Seiten zu studiren; 
die künftigen Forschungen werden zeigen, in wie weit die hier gestellten Hypothesen haltbar sind."

Und eben diesem Programm folgend, suchte ich durch das Experiment der Frage näher zu treten, um einen Wegweiser bei den künftigen Untersuchungen am Mensehen zu gewinnen.

Bevor ich aber meine Resultate auseinandersetze, ist es rathsam; nachzusehen, was für eine Stellung die Autoren in dieser Frage angenommen, und was die Forschungen über das Ganglion ciliare, seine Natur und Function bisher ergeben haben.

Moeli $\left({ }^{3}\right)$ äussert sich kurzweg in einer Note folgendermaassen: „Der Umstand, dass (Langendorff) das Ganglion ciliare in die Bahn der Irisinnervation eingeschaltet ist, dürfte für die Frage nicht von Bedeutung sein. Das Reflexcentrum im Ganglion ciliare selbst zu suchen, wird kaum angehen."

Da ich, soviel mir bekannt ist, der Erste und vielleicht der Einzige bin, welcher das Ciliarganglion als ein wirkliches Pupillencentrum ansieht, so glaube ich, obwohl mein Name nicht genannt ist, dass diese letzte Bemerkung eben auf meine Theorie sich bezieht. Da aber diese Frage von Moeli nur en passant erörtert wurde und er selbst keine Gründe anführt, so werde ich mich begnügen, später meine Ansichten über diese Frage auseinanderzusetzen.

Bach $\left(^{4}\right)$ hat gefunden, dass, wenn man Iris und Corpus ciliare entfernt, im Oculomotoriusgebiet keine Veränderungen auftreten, wohl aber im Ganglion ciliare derselben Seite. Vor Kurzem erschien jedoch ein Originalbericht über neue Studien desselben Autors, worin er zur Feststellung der Lage des Reflexcentrums der Pupille an Affen, Katzen und albinotischen Kaninchen Decapitationen ausführte. Nach einfacher, selbst sehr hoch ausgeführter Decapitation war die directe und indirecte Reaction auf licht noch prompt vorhanden. Es blieb hierbei stets ein verschieden langes Stück Halsmark zurück. Nachdem B. von G. Wolff mitgetheilt worden war, dass dieser auf Grund seiner Untersuchungen die reflectorische Pupillenstarre bei Tabes und Paralyse auf eine Degeneration der Hinterstränge des oberen Halsmarkes zurückführe, zerstörte er das bei der Decapitation zurückbleibende Stück Halsmark und fand, dass auf diese Weise die Pupillenreaction sofort erloschen war. Durch diese Versuche glaubt Bach nachgewiesen zu haben, dass das Reflexcentrum der Pupille in den allerobersten Partien des Halsmarks gelegen ist.

Von grosser Bedeutung ist die ausführliche Publication Bernheimer's ( $\left.{ }^{5}\right)$. Der Autor mit der Competenz und Gründlichkeit, welche ihm eigen sind, nahm planmässig Experimente an Affen vor. Er exstirpirte einen nach dem anderen alle äusseren Muskeln des Bulbus 
und untersuchte den Oculomotoriuskern mit der Nissl'schen Methode. Er fand in verschiedenen Kernen Degenerationen, beobachtete aber bei diesen Experimenten, dass ein paar Zellengruppen intact blieben; er liess die Augenmuskeln intact, vollführte die Exenteratio bulbi, zerstörte somit die inneren Augenmuskeln und fand nur jene Kerne lädirt, welche sich bei den früheren Versuchen intact erwiesen.

Auf Grund dieser Beobachtungen schreibt er S. 500 ...... Folgendes: „Die an und in der Mittellinie in der proximalen Hälfte des Oculomotoriuscentrums befindlichen Nebenkerne, der paarige, kleinzellige Mediankern und der grosszellige, unpaarige Mediankern, sind, wie ich schon früher anatomisch nachgewiesen, wahre Oculomotoriuskerne und ganz speciell als Centrum der vom Oculomotorius versorgten Binnenmuskeln des Auges aufzufassen. Der kleinzellige Mediankern der rechten Seite gehört dem rechten Auge an, der grosszellige unpaarige Mediankern versorgt beide Augen, doch sind die das rechte Auge versorgenden Zellen mehr rechts, die des linken mehr links, also gleichseitig, angeordnet. Der sogenannte obere laterale Oculomotoriuskern von Darkschewitsch gehört nicht zu dem Ocnlomotorius."

In seiner zweiten Arbeit unterzog Bernheimer die Haltbarkeit meiner Hypothese über die Bedeutung des Ganglion ciliare einer experimentellen Prüfung. Er exenterirte den Bulbus und fand alle Zellen des Ganglions mehr oder weniger degenerirt, "ganz normal aussehendeZellen sind in keinem Schnitt zu finden". Um weiter festzustellen, ob die aus den Zellen des Ganglion ciliare austretenden Nervenfasern thatsächlich nur die Iris und das Corpus ciliare versorgen, zerstörte er durch Cauterisation die Cornea bis auf die Membrana Descemeti und fand: "Während damals alle Zellen degenerirt waren, dürfte diesmal ungefähr etwa der sechste bis fünfte Theil aller Zellen degenerirt gewesen sein". Bernheimer kommt zu folgenden Schlüssen: „Im Ganglion ciliare des Affen wurzeln Nervenfasern; welche nicht allein die Jris und den Ciliarkörper, sondern sicherlich auch die Hornhaut versorgen. Wenn wir, wie ich glaube, annehmen können, dass beim Menschen dieselbe anatomische Thatsache vorliegt, dann ist die Hypothese, dass eine primäre Erkrankung des Ganglion ciliare eine isolirte Pupillenstarre hervorrufen könne, entschieden von der Hand zu weisen. Es müssten nothwendig bei einer Erkrankung der Zellen des Ganglion ciliare gleichzeitig Störungen in der Hornhaut mit auftreten, eine Erscheinung, welche bis jetzt, soviel ich weiss, noch niemals im Zusammenhang mit reflectorischer Pupillenstarre beobachtet wurde. Dass es sich andererseits um eine elective primäre 
Erkrankung jener Ganglienzellen handle, welche Nervenfasern zur Iris und zum Ciliarkörper senden, ist wohl von vornherein ausgeschlossen, um so mehr, da in den einzelnen Schnitten vielfach degenerirte und normale Zellen miteinander vermischt waren."

In der Gesellschaft der Aerzte in Wien (26. März 1897) äusserte sich Bernheimer wie folgt: „Es schien mir von vornherein unwahrscheinlich, dass das Ganglion ciliare als eine Art peripheres Centrum der Irismuskeln aufgefasst werden konnte, da wir ja der Annahme huldigen, dass dies Ganglion, wie alle periphere Ganglien, ein sensorisches sei, und dass die motorische Wurzel des Oculomotorius nicht in das Ganglion aufgeht, sondern demselben nur anliegt, wie ich mich aus mikroskopischen Präparaten auch neuerdings überzeugen konnte." Und weiter unten: "Hiermit ist der Beweis geliefert, dass das Ganglion ciliare thatsächlich ein sensorisches Ganglion ist, und dass die von ihm abgehenden Ciliarnerven sensorische Nerven sind, welche die Hornhaut, die Binnenmuskeln und die Augenhäute überhaupt versorgen."

Gehen wir jetzt auf die Ansicht der Autoren über die Natur des Ganglion ciliare tuber: Nach Schwalbe (6) gehört das Ganglion ciliare als spinales Ganglion dem Oculomotorius an. Man unterscheidet eine motorische (Oculomotorius), eine sensible (Trigeminus) und eine sympathische Wurzel. 'Die erste stammt aus dem zum Obliquus inf. verlanfenen Zweige des Oculomotorius, ist dicker wie die übrigen, zuweilen in zwei Fäden getheilt und geht zum unteren Winkel des hinteren Randes vom Ganglion ciliare. Die zweite als Radix longa kommt aus dem Nasociliaris und verbindet sich mit dem oberen Winkel des hinteren Randes. Sie führt dem Ganglion sensible Nervenfasern zu. Die dritte wird von feinen Fäden gebildet, die aus dem die Carotis interna im Sinus cavernosus umspinnenden sympathischen Plexus zwischen den beiden vorigen zum hinteren Rande des Ganglion ciliare gelangen sollen; die meisten Fasern sollen dasselbe in der Bahn des Oculomotorius gewinnen, einige auch in der des Nasociliaris, einige wenige gehen auch am Ganglion direct vorbei in die Ciliarnerven über.

Vom Ganglion ciliare entspringen 3-6 Nn, ciliares breves, welche vor ihrem Eintritt in den Augapfel durch mehrfache Theilung sich bis auf 20 vermehren, sie zerfallen in eine obere (laterale) und eine untere (mediale) (Gruppe, welche den Sehnerven umgeben und neben ihm zum Augapfel gelangen. Denselben Weg schlagen die aus dem N. nasociliaris entspringenden Nn. ciliares longi ein, sie gesellen sich zur unteren medialen Gruppe der kurzen Ciliarnerven, deren einer sich mit einem der beiden Nn. ciliares longi verbindet. „Die Ciliarnerven, deren Faserzahl eine bedeutend grössere ist, als die der eintretenden drei Wurzeln (so dass demnach im Innern des Ganglions eine bedeutende 
Faservermehrung in Verbindung mit dem Auftreten von Ganglienzellen statuirt werden muss) führen dem Augapfel motorische und sensible Nervenfasern zu, ferner Fasern, die in der Bahn des Sympathicus zum Ganglion gelangen und eine sehr verschiedene physiologische Bedeutung haben können."

Retzius ( $)$ fand, dass nach der Beschaffenheit ihrer Nervenzellen und der Ausläufer (unipolare) derselben das Ganglion jugulare und der Plexus gangliformis nervi vagi, das obere und untere Ganglion des N. glossopharyngeus, das Ganglion geniculum des Facialis und das Ganglion semilunare trigemini mit den Spinalganglien vollkommen übereinstimmen; die Nervenzellen des Ganglion oticum, nasale und linguale rechtfertigen durch ihre multipolare Form die allgemeine Annahme, dass dieselben dem sympathischen System angehören. Aber auch in dem Ganglion ciliare fand Retzius nur multipolare Zellen und spricht sich demnach gegen die von Schwalbe auf vergleichend-anatomischem Wege versuchte Deutung dieses Ganglion als eines Wurzelganglions des $\mathrm{N}$. oculomotorius aus.

Kölliker(8) betont (S. 854) den von Lengley, Anderson und Langendorff geführten Beweis, dass der Oculomotorius nicht direct auf den Sphincter pupillae einwirkt, sondern nur durch Mitbetheiligung des Ganglion ciliare. Kölliker fasst das Ganglion ciliare als ein sympathisches Ganglion auf, weil es nur multipolare Zellen besitzt. Nach ihm sind alle Nervuli ciliares cellulifugal wirkende, und ,es muss ganz bestimmt hervorgehoben werden, dass unter den Ganglienfasern keine centripetalwirkende, keine sensible Elemente vorkommen. Alle sensiblen Functionen in diesem Gebiete werden einzig und allein durch cerebrospinale Fasern vermittelt" (S. 857).

A polant $\left({ }^{9}\right)$ giebt zu, dass das physiologische Experiment für eine Zugehörigkeit des G. ciliare zum Oculomotorius spricht, suchte aber die Frage mit Benutzung der Degenerationsmethode zu entscheiden. Er durchschnitt an jungen Katzen rom Rachen her den Oculomotorius nahe der Hirnbasis, tödtete die Thiere nach 8-14 Tagen und fand Degeneration des Oculomotorius und einer Wurzel des Ganglion ciliare; im Ganglion selbst war keine Degeneration. Apolant schliesst daraus, dass das G. ciliare dem Sympathicus zugehöre.

Nach Kra use ist das Ciliarganglion wahrscheinlich gemischter, nach Michel sympathischer Natur und van Gehuchten*) ist geneigt dem Ganglion eine spinale Natur zuzuschreiben.

*) citirt von Holtzmann. 
Das Neuron des Ganglion ciliare u. die Centra der Pupillenbewegungen. 363

Chiarugi ( $\left.{ }^{10}\right)$ äussert sich mit einer gewissen Reserve. Er ist geneigt anzunehmen, dass das Ciliarganglion nicht aus dem dritten Nervenpaare stamme, weil er im ganzen Verlauf des Oculomotorius keine Ganglienzellen fand, ausgenommen in seiner Wurzel. Es ist wahrscheinlicher, dass das Ganglion sich aus der Radix ophthalmica ausbilde, welche viele Zellengruppen besitzt; das Ganglion würde sich sehr frühzeitig aus jener losmachen und in Beziehung zu dem Oculomotorius treten.

Holtzmann (11) studirte histologisch das G. ciliare und die Ciliarnerven bei Amphibien, Vögeln und Säugern, und zwar vergleicht er die Spinalganglien und die sympathischen Zellen mit jenen des Ganglion ciliare. Er fand:

Bei Fröschen die Spinalganglienzellen von kleinerer und grösserer Form, einige mit T-förmigen Fortsätzen, alle mit excentrischem Kern und Nucleolus. Die sympathischen unterscheiden sich wenig von den oben genannten Zellen, sind kleiner und besitzen einen excentrisch gelagerten Kern und Kernkörperchen. Im Oculomotorius fand er spinale Elemente.

Bei Vögeln sind die Kerne und Kernkörperchen der Spinalganglienzellen stets central; bei den sympathischen Elementen sind die Nissl'schen Schollen derber, die Zellen kleiner als die erstgenannten, der Zellkern liegt annähernd central. Das Ganglion ciliare ist ei-kreisförmig begrenzt und es liegt dem Stamm des Oculomotorius direct an; die Nervenfasern der Ciliarnerven besitzen dicke Markscheiden. Die Zellen wiederholen nun weder genau den Typus der spinalen, noch der sympathischen Zellen. Keine Fortsätze, die sich in das pericelluläre Gewebe hineinerstrecken, wie bei den sympathischen Zellen, dagegen erinnert das intercelluläre Bindegewebe mehr an die sympathischen Ganglien. Holtzmann resumirt diese Ergebnisse mit den Worten: "Ich habe daher keinen Grund, an der rein spinalen Natur der Zellen des Ciliarknotens der Vögel zu zweifeln."

Beim Hunde beobachtete er häufig individuelle Schwankungen, er theilt die Ansicht Schwalbe's, dass manchmal von den beiden Wurzeln die eine direct in einen Ciliarnerv übertritt. In den Spinalganglienzellen finden sich annähernd kreisförmig begrenzte, selten ausgesprochene längliche Zellen. Der Kern liegt im Centrum, nur in exquisit länglichen Formen ist er etwas zur Seite geschoben mit centralem Nucleolus. Die Schollen liegen cuncentrisch um den Kern geschichtet. Eine verschieden hochgradige Entfärbung der Grundsubstanz der Zellen ist eine sehr gewöhnliche Erscheinung und gerade die am stärksten entfärbten Zellen scheinen die grössten Schollen zu besitzen; häufige Vacuolen stellen nur schollenarme Partien dar. Die 
Zellen im Ganglion cervicale supr. sind erheblich kleiner, der Kern steht fast in allen Zellen ganz nahe der Peripherie; mit Thioninfärbung erkennt man stets einen deutlichen Ring dicker, plumper Schollen an der Peripherie der Zellen; der centrale Ring um den Kern ist geringer ausgebildet; zwischen beiden liegt ein hellerer Raum, der von Schollen viel feineren Kalibers bevölkert ist. Das bindegewebige intercelluläre Stroma ist kräftiger als das der Spinalganglienzellen entwickelt. Im Ciliarganglion konnte H. mit Sicherheit die beiden beschriebenen Zellenarten nachweisen; die spinalen Elemente schienen die anderen zu übertreffen, das ist aber nicht constant. Man findet. (durch die Golgi'sche Methode) uni- und bipolare Formen.

Bei Katzen dagegen sind die Zellen des Ciliarganglions rein sympathischer Natur, höchstens können die unipolaren Zwergzellen als Zeugen der ursprünglichen gemischten Anlage gelten.

Bei Kaninchen besitzen die Spinalganglienzellen einen centralen Kern, die sympathischen Zellen sind kleiner, multipolar und haben zwei Kerne (nicht alle), die des Ciliarganglions haben einen central stehenden Kern, die meisten sind mit zwei Ausläufern versehen, welche nahe bei einander die Zelle verlassen, seltener geht nur ein einziger dichotomisch gebildeter Fortsatz ab. Holtzmann fasst diese Zellen als spinale Zellen auf, ausserdem aber kann man ein, wenn auch variables, mächtig ausgebildetes System symp. Elemente in der Orbita erkennen.

Der Autor bemerkt zuletzt: „Erinnern wir uns der wohl kaum bestrittenen Thatsache, dass die Spinalganglien sowohl als die sympathischen Ganglien des Grenzstranges aus gemeinsamen Anlagen, den Intervertebralganglien, hervorgehen, so erklärt man sich die doppelte Natur des Ciliarganglions leicht, wenn wir ihm die Bedeutung eines solchen Intervertebralganglions zuschreiben und annehmen, dass in ihm bald die eine, bald die andere Seite der ursprünglichen Anlage zur Entwicklung gelangt."

Antonelli (12) stätzt sich auf die Ergebnisse der vergleichenden Embryologie, auf das Studium der Structur des Ciliarganglions und auf die histochemischen Charaktere der Zellen und kommt zu dem Schlusse, dass das Ciliarganglion nicht nur ein Analogou eines Spinalganglions sei, sondern auch, dass es dem dritten Paare zugehört. Die Radix brevis ist von keinem gesonderten, aus dem Oculomotorius stammenden Nervenbündel gebildet, sondern gehen die einzelnen Fasern unregelmässig aus dem ganzen Nervenstamm in die Radix brevis hinein. Manchmal findet man unter den myelinisirten Fasern auch einzelne, weJche den Charakter der sympathischen Fasern besitzen und welche aus dem Sympathicus selbst stammen. 
Das Neuron des Ganglion ciliare u. die Centra der Pupillenbewegungen. 365

Antonelli glaubt, dass aus denselben Fasern ein unbeständiges Würzelchen entsteht, welches manchmal vom Abducens zum G. ciliare hinzieht. In der Rad. brevis fand Antonelli bei Menschen manchmal ein accessorisches Ganglion eingebettet.

Der Autor ist der Ansicht, dass das G. ciliare dem G.jugulare vagi ähnlicher sei (also indirect ähnlicher einem Spinalganglion), als dem Ganglion symp. sup., denn die Zellen sind denen des Spinalganglion gleich, sogar unipolar, sicher nicht multipolar; das asteroide Aussehen dieser Nervenzellen ist die Folge entweder cadaveröser Beschädigungen oder unpassender Fixationsmethoden.

D'Erchia ( $\left.{ }^{13}\right)$ sagt: Die Golgi'sche Methode bat uns deutlich Charaktere gezeigt, welche sehr wahrscheinlich für die sympathische Natur des Ganglion ciliare sprechen; kaum glauben wir aber, dass dieses histologische Kriterium uns zwingt, das Ciliarganglion morphologisch als ein sympathisches Ganglion zu betrachten. Er studirte das Ganglion bei dem Huhn, bei dem Rind, bei welchem letzteren er Zellen im Oculomotoriusstamm fand. Er constatirte ferner, dass die sensorische Wurzel direct aus dem G. Graseri entspringen kann. Bei dem Hunde bemerkte D'Erchia, dass die sensible Wurzel Fasern sowohl aus dem N. nasale als aus dem Oculomotorius enthält.

Das Studium des Ganglion ciliare beim Mensehen ist besonders wichtig.

Bei einem $21 \mathrm{~cm}$ langen Fötus fand er Zellen sowohl in dem Stamm des Nerven für den Obliquus inf. (nahe der kurzen Wurzel) als im Oculomotorinsstamm selbst, die Radix longa enthält wie bei dem Hunde zwei feine Fäden, den einen aus dem Nasociliarnerv, den anderen aus dem R. superior des Oculomotorius. Einige Zellengruppen befinden sich in den Ciliarnerven selbst, bis knapp hinter der Sclera. Bei Neugeborenen ist die Rad. brevis aus fünf Fasern zusammengesetzt, deren vier ins Ganglion eindringen, während die andere; längere Wurzel aus drei Fäden besteht. Die eine Faser entspringt aus dem Ramus für den Obliquus inf., die zweite aus dem Oculomotoriusstamm, die dritte aus dem Ramus sup. desselben Nervs. Die Radix longa besteht aus zwei Fasern, deren eine zellenarm, die andere zellenreich ist, und sie bilden die Radix plexiformis. In der Nähe des Ganglion ciliare fliessen alle diese Fasern zu einem gemeinsamen zellenreichen Stamm zusammen, und aus diesem entspringt eine Faser, welche sich an das Ciliarganglion anlehnt und als Ciliarnerv weiter verläuft. Von dem Hauptganglion wenig entfernt, findet man ein accessorisches Ganglion, welches zwei Ciliarnerven aufuimmt und einen Ramunculus zu dem Oculomotorius abgiebt.

Deutsche Zeitschr. f. Nervenheilkunde. XIV, Bd. 
Bei Erwachsenen beobachtet man eine Menge Variationen in der Radix brevis; die Zahl der Fäden variirt zwischen 2-4, deren eine Wurzel, die dickste, die wahre Radix brevis ist. $\mathrm{Z}$ wischen diesen Fasern findet man einige Nervenzellen; man beobachtet auch Radices breves, welche die Structur des Ganglions vollständig nachahmen. Für die Radix longa muss man die Multiplicität der Fäden hervorheben, und manchmal tritt durch dieselben eine Wurzel ins Ganglion hipein, welche aus dem Oculomotorius kommt.

Gegenüber Antonelli fand D'Erchia, dass nur einige Bündel der sensorischen Wurzel das Ganglion einfach durchziehen, dass aber der grösste Theil der Radix ins Ganglion bineintritt, und sich zwischen die Elemente desselben zertheilt, so wie die Fäserchen der Radix motoria.

Dies geschieht auch beim Hnnd und beim Rind.

Man sieht aus allen diesen wichtigen Literaturauszügen, wie verschieden und auseinandergehend die Ansichten der Autoren über die Natur und die Verbindungen des Ganglion ciliare sich gestalten. Dieses Organ, welches schon bei den Amphibien als Zellen des Oculomotorius vorhanden ist, variirt, was die Natur desselben anbelangt, für jede Klasse und jede Species. Es giebt Ciliarganglien, welche lauter sympathische oder spinale Elemente, einige, welche sowohl die einen wie die anderen Formen enthalten. Antonelli betont die trügerischen Bilder, welche durch cadaveröse Zustände und unpassende Fixationsmethoden entstehen können, und mit vollem Recht, und D'Erchia hebt mit ebenso vielem Recht hervor, dass aus der Uni- oder Isopolarität der Nervenzellen allein sich nicht die wahre Natur des Ganglions kundgiebt, man muss alle Merkmale zu Hülfe nehmen. Die genetischen Kriterien aber sind auch widersprechend, denn die vergleíchend-anatomischen Studien führten Schwalbe und Antonelli zu einem, Chiarugi zu einem anderen Schluss.

Man sieht ferner, wie inconstant von Species zu Species, ja von Individuum zu Individuum die Vertheilung und der Zusammenhang der Wurzeln mit dem Ganglion sind, so dass es möglich ist, dass Oculomotoriusfasern durch die Radix longa mit dem Ganglion in Verbindung treten.

Ich werde jetzt zu meinen eigenen Experimenten und Untersuchungen übergehen, vor Allem muss ich aber meinen verbindlichsten Dank Herrn Dr. Cofler aussprechen, der mit grosser Aufopferung, meinen Wünschen entspreehend, sehr oft gegen unerwartete Schwierigkeiten 
kämpfend, die von mir verlangten operativen Eingriffe musterhaft vollführte.

Die erste Reihe der Fxperimente wurde an Hunden ausgeführt, und je mehr ich mich in das Studium vertiefte, desto weiter erstreckte sich das Feld der Untersuchungen, so zwar, dass ich bei der zweiten Reihe von Experimenten, an Affen, nicht nur das Ciliarganglion, sondern auch andere Organe methodisch studirte.

Da mir unbekannt ist, dass Jemand in solcher Ausdehnung dieses Thema experimentell behandelt habe, so erlaube ich mir das darauf Bezügliche, wenn auch nicht vollständig, doch ausführlich wieder zu geben.

Bei diesen Versuchen wurden verschiedene Fixationsmethoden angewendet, meistens 96 proc. Alkohol und die von mir angegebene Lösung $\left({ }^{14}\right)$, die mit einigen von mir eingeführten späteren Modificationen für alle die gebräuchlichsten Färbungen passt und die Zellen sehr gut fixirt. Ich muss mir erlauben die Methode wieder anzuführen: Die Stïcke kommen gleich nach der Heransnahme in folgende Iösung: $100 \mathrm{ccm} 95$ proc. Alkohol, im welchem $1 \mathrm{dg}$ Chromsäure gelöst wird; nach der Lösung fügt man $5 \mathrm{ccm}$ Formol hinza. Die Lösung muss jeden Tag gewechselt werden und in 1 bis 8 Tagen, je nach der Grösse des Stückes, ist die Fixation vollendet. Die Stïcke werden dann in 95 proc. Alkohol (nicht zu lange) anfbewahrt oder mit Syntheticon anfgekittet und ohne Inclusion unter 95 proc. Alkohol geschnitten. Kleine Stücke (Ganglien) werden in der üblichen Weise in Paraffin eingebettet. (Eine bis vier Stunden in absolutem Alkohol, eine Stunde in wenigstens zweimal gewechseltem Chloroform oder Xylol, eine Stunde in Chloroform- oder Xylolparaffin, eine Stunde in Paraffin bei $\left.48-52^{\circ}\right)$. Die Schnitte werden nach Befreiung von Parafin weiter behandelt. Ich benütze alle die Farbenflüssigkeiten kalt; so lasse ich die Schnitte bei Zimmertemperatur 24 Std. in Niss l'schem Methylenblan, 5-10-30 Min. und mehr, wenn es nöthig ist; in concentrirter Thioninlösung, nach meiner Fixationsmethode ist ein längeres Verweilen der Schnitte in der Farbe nothwendig, drei bis vier Stunden im Toluidenblau, 24 Std. in verdünnter Ehrlich'sches Triacid-Lösung, während die v. Gies on'sche Methode ganz gut wie gewöhnlich gelingt; man kann aber mit Nutzen auch vorher die Schnitte 24 Std. in einer wässrigen 2 proc. Bichromatlösung stehen lassen. Für die W ei g ert'sche Markscheidenmethode verfahre ich folgendermaassen: Die Schnitte bleiben 24 Std. in einer 1 proc. wässrigen Chromsäurelösung, dann kommen sie nach zweimaliger Waschung in die Weigert'sche (dicke Schnitte) oder in die Auerbach'sche Chloralmolybden-Hämatoxylinlösung (dünne Schnitte), worin sie noch einmal 24 Std. verbleiben. Von da werden die gut gewaschenen Schnitte in die von Vassale modificirte Kupferlacklösung (gleiche Theile Kupfer- and Lithionlösung, der Niederschlag wird mit Ammoniaktropfen gelöst) gebracht. Hierin bleiben sie mindestens $10 \mathrm{Min}$., werden dann sehr gut gewaschen und nach Weigert sorgfältig differenzirt. Will man eine sehr gate Differenzirung bekommen, so kann man, dem mündlichen Rath Donnaggio's folgend, nach einer gründlichen Waschung für sehr kurze Zeit (1-2 Min.) die Schnitte in eine 2 proc. Kali causticum-Lösung bringen, man muss aber nachher 
lange und in 2-3 Wasserschalen dieselben waschen, sonst werden sie nach einem Tag blan-grün verfärbt. Zuletzt werden die Schnitte in der üblichen Weise bis zur Inclusion weiter behandelt.

Um das Ganglion ciliare an finden, muss man vor Allem das Auge sammt Opticus und Oculomotorius so vollständig herausnehmen, dass der Boden der Orbita ganz ausgeräumt wird; man läuft sonst Gefahr das Ganglion in der Orbita zurückzulassen. Man suche dann den M. obliquus inf. auf, der durch die schrägen, am Bulbus selbst verlaufenden Fasern gut erkennbar ist. Man dringt an dieser Stelle durch das Fettgewebe hinein und so kommt man leicht neben dem Opticus zu den Ciliarnerven, man geht längs dem Opticus weiter und bald ist anch der Nerv für den M. obliqu. inf ersichtlich; durch diese beiden Nerven als Wegweiser fährt man immer längs den Ciliarnerven vorsichtig präparirend weiter und bald kommt man zum Ganglion. Man befreit dasselbe von dem umgebenden Gewebe, und wenn das Organ mit allen Wurzeln und Ciliarnerven deutlich zu Tage liegt, wird dasselbe mit dem Stück Nerv (R. f. den Obliquus) sammt Wurzeln und Ciliarnerven vorsichtig abgeschnitten und herausgenommen. Man breitet das Präparat auf einer Glasplatte aus, befreit es von dem übriggebliebenen Fettgewebe und von den in einer anderen Weise zu behandelnden Ciliarnervenfasern, giesst auf das Ganglion und Adnexa die Fixationsflüssigkeit und bringt dasselbe nach 5 Minuten in eine mit der frischen Flüssigkeit erfüllte Eprouvette; das Präparat bleibt mit seinen Adnexa ganz gut ausgedehnt.

Experimente an Hunden.

Da ich die anatomischen Angaben Holtzmann's durchaus bestätigen kann, gehe ich gleich zu den Experimenten über. Augen.

I. Hund A, klein, grau, gekreuzter Rasse, mit stark vorspringenden

17. Juni 1897. Die Aufgabe war, die Ciliarnerven zu durchschneiden, ohne die vom Oculomotorius innervirten Muskeln zu lädiren; deswegen wurde nach einer 1 proc. Morphiuminjection und Einträufelung von 4 proc. Cocainlösung in den Conjunctivalsack und 2-3 Einspritzungen von einer 1 proc. Cocainlösung in die Conjunctiva selbst die Commissura externa palp. bis zum Knochen rechts gespalten. Der Conjunctivalsack wird geöffnet und der Externus excidirt. Man sucht vergebens den Opticus mit einem Haken zu fangen; man entfernt ein Stück Processus zygomaticus orbitalis, es gelingt trotzdem nicht den Opticus zu isoliren, deswegen wurde der Opticus sammt den Ciliarnerven durchschnitten.

Copiöse Hämorrhagie. Verlauf normal. Keratitis neuroparalytica (Dr. Cofler).

Das Thier wurde am elften Tage nach der Operation durch Chloroform getödtet. Rechts waren beide Opticusstümpfe circa zwei Millim. von einander entfernt, die Ciliarnerven vollständig durchtrennt. Es wurden beide Ciliarganglien, Optici, Oculomotorii, die Spinalganglien cervic. VIII und thorac. I und II sammt Wurzeln, sowie die Centralregion des Oculomotorius aufbewahrt. Die peripheren Nerven und die Spinalwurzeln wurden nach Marchi, die anderen Organe nach meiner Fixationsmethode behandelt, die Ganglien in Paraffin eingebettet, das vordere Stammhirn durch Syntheticon angeklebt und ohne Imprägnation in Serien geschnitten und studirt. 
Linkes G. ciliare (nicht operirte Seite). Einige Schnitte sind mit Thionin, andere mit Methylenblau gefärbt worden, die erste Färbung schien mir besser zu gelingen.

Die Ganglienzellen, grössere und kleinere (Holtzmann), waren sehr wenig geschrumpft, viele reichten sogar bis zur Kapsel, man findet das Tigroid sehr gut gefärbt und normal. Die grösseren Zellen sind mit etwas gröberen, nicht immer concentrisch gerichteten Chromatinschollen besäet, die kleineren durch ein feineres, etwas blässer gefärbtes Tigroid gekennzeichnet; die Peripherie der Zellen war als blasser, schollenfreier Saum sichtbar. Mit Delafield'schem verdünntem Hämatoxylin (nach Lugaro) erscheint die Grundsubstanz punctirt (Object E Zeiss Comp. a e b). Die normale Kapsel ist mit ibren Endothelien vollständig bekleidet. Der meist centrale Kern sitzt in einigen Zellen auf einer Seite, mit der normalen feinen Punctirung versehen; in wenigen Elementen erreichte er sogar die Peripherie. Das Kernkörperchen ist meistens auf einer Seite orientirt, nie aber sah man den Kern buchtförmig die Zelle anstreiben. Das intercelluläre Bindegewebe normal, mit normalen, zahlreichen Kernen. Durch die Weigert-Vassalesche Methode fand ich die scheinbar durchziehenden und die im Ganglion selbst endenden Nervenfasern vollständig normal. Im Protokoll ist noch Folgendes notirt: Die grossen Zellen sind den mittleren Formen der Spinalganglien, die kleinen jenen der sympathischen Zellen ähnlich.

Rechtes Ganglion ciliare (operirte Seite). Keine Zelle ist normal; alle sind mehr oder weniger geschrumpft, mit gezackten Rändern. Die meisten Zellen blass, von glasigem Aussehen, lassen kein Tigroid mehr erkennen. Andere scheinen wie eine geschrumpfte, dunkelblaue Masse mit oder ohne unterscheidbare dunkle, meistens an der Peripherie zusammengeworfene Schollen; andere Elemente endlich sind fast farblos, und nur an der Peripherie sieht man formlose, dunkle Massen. Bei den Zellen der ersten und bei wenigen der dritten Kategorie buchtete der Kern einen Theil der Zellperipherie aus, so zwar, dass man den Nuclens flaschenförmig aus der Zelle hinaustreten sah, und er selbst mit der Zelle nur durch einen dïnnen Hals verbunden war. Bei diesen Elementen war das Kernkörperchen immer in dem vortretenden Theil des Kerns; jedoch freie, d. i. vollständig aus der Zelle herausgewanderte Kerne oder Kernkörperchen kounte man nicht finden. Die feine Punctirung des Kerns war in ailen Elementen bei Thioninfärbung verschwunden, bei Ehrlich'scher Färbung sah man eine Anzahl gleich grosser Punkte.

An einigen Zellen sah man strahlenförmige Fäserchen als Kapselreste; durch Hämatoxylin sind Zellen von einer Art Spinnenfäden durchzogen wahrzunehmen, während einige Fäden sogar die Kapsel erreichen. Alterationen zeigten weder das intercelluläre Gewebe noch die Nervenfasern.

Die Ciliarnerven der operirten Seite (Zupfpräparate nach 24 stündiger Fixirung in einer 1 proc. Ueberosmiumsäurelösung) waren vollständig degenerirt.

Centrale 0culomotoriusregion. Vor Allem muss ich bemerken, dass die Elemente ein ganz normales Aussehen hatten, sowohl rechts als links, sowohl in der mittleren als in der äusseren, in der proximalen wie in der distalen Region. Die Zellen sind gut fixirt und gefärbt, ihre Fortsätze weit zu verfolgen. Das Tigroid (Thionin, Methylenblan), sowie die Kerne und Kernkörperchen normal. Hie und da, ohne Regel, in den 
verschiedensten Regionen, im Centralgrau wie in den Gegenden der Substantia nigra und in der Raphe, sind einige stärker gefärbte Zellen vorhanden. Man sieht die chromatiscbe Substanz als tief-blaue Linien auf einem dunkelblauen Grund. Gegen den Nervenfortsatz zu wird die Grundsubstanz beller und das Chromatin deutlicher; bei diesen Zellen sind nanchmal die Fortsätze nicht so weit, wie bei den anderen Zellen, zu verfolgen. Hie und da sind einige Elemente wie geballt; das fand ich besonders in den Gegenden der Substantia nigra und im Centralgrau am Boden des 3. Ventrikels. Keine Zelle zeigte Chromatolysis, Verkleinerung oder Vergrösserung des Kerns. Je nach der Schnittführung wechselt das Aussehen einiger Zellen, so dass neben vollständig angebildeten Elementen auch Bruchtheile derselben zu sehen sind; man findet aber auch in allen Zellengruppen des Oculomotorius grössere und kleinere Zellen. Die Präparate, welche mit der WeigertVassale'schen Methode behandelt wurden, zeigten vollständig normale Markfasern und das Reticulum sehr gut ansgebildet.

Die Schnitte ans dem centralen Stumpf des nach Marchi fixirten rechten Opticus zeigten viele schwarze feine Pünktchen (für eine kurze Strecke), jene aus dem rechten Oculomotorius und aus den Spinalwurzeln keine. Spinalganglien normal.

Dieses Experiment zeigte mir das Prototyp der bei Läsion der Ciliarnerven eintretenden Veränderungen im Ciliarganglion und hatte für die Frage die Bedeutung eines Grundexperiments. Wenn das Ganglion ciliare keine Alterationen gezeigt hätte, so wäre die ganze Frage durch diese negative Antwort experimentell, wenigstens für diese Thierspecies, gelöst gewesen. Ich konnte aber mit Sicherheit annehmen, dass nach Neurectomia optico-ciliaris die Nervenzellen des Ganglion ciliare vollständig degeneriren. Das Experiment belehrte mich ferner, dass die Centralregion des Oculomotorius normal war, da ich als nicht durch das Experiment alterirte Zellen jene wenigen Elemente betrachten konnte, welche die geschilderten Verschiedenheiten in der Färbung und Gestalt zeigten, und die in den verschiedenen Regionen zu finden waren.

Die negativen Befunde bei der Weigert'schen Färbung und die geringen Alterationen bei der Marchi'schen Methode sind durch die kurze Zeit, welche zwischen Experiment und Tödtung verflossen, hinlänglich erklärt.

II. Hund B, schwarz, von mittlerer Grösse, gekreuzter Rasse.

28. Juni 1897 Kauterisation der rechten Cornea. ${ }^{1)}$ Da die Cornea bei starkem Auseinanderziehen der Lider nicht ganz zu übersehen war, wurde die Commissura externa gespalten. Instillation einer 4 proc. Cocainlösung in den Conjunctivalsack.

Es wird der Liderweiterer applicirt; der Assistent fixirt mit einer Pincette das dritte Lid, mit einer zweiten fixirt der Operateur den Bulbus, und mit einem glühenden, spiralgedrehten Platinfaden wird die ganze Cornea bis zur Descemeti kauterisirt. Die Commissura wird zusammengenäht und das Thier frei gelassen. Verlanf glatt (Dr. Cofler).

Tödtung am zwölften Tage. Fixation im 96 proc. Alkohol.

1) Dieses Experiment und die folgenden wurden nach der Bernheimerschen Mittheilung in der Wiener Gesellschaft der Aerzte vorgenommen. 
Linkes Ganglion ciliare (der nicht operirten Seite). Die Zellen normal, aber die Schrumpfung viel mehr ausgesprochen als beim Hund A (Fixationsmethode?).

Rechtes Ganglion ciliare (der operirten Seite). Die Alteration der Zellen ist im Vergleich zu jenen des ersten Hundes, dem Grad der Veränderungen und der Zahl der getroffenen Elemente nach, bedeutend verschieden. Nur jede 6.-8. Zelle war in Degeneration begriffen. Keine ist farblos oder zu einem schwärzlichen Klümpchen redncirt. Das Tigroid der lädirten Zellen ist mässig rareficirt oder zeigt eine periphere Chromatolysis; der Kern ist manchmal geschwollen (vacuolisirt?), wandständig, manchmal gegen die Peripherie scheinbar offen, so dass man in der Zelle eine mit kurzem Halse versehene flaschenförmige Vertiefung sah, in welcher das Kernkörperchen lag. Einige Zellen (die kleinen) sind dunkel gefärbt, mit undeutlichem Nucleus. Das Kernkörperchen zeigte keine deutliche Alteration.

Linkes Ganglion Gasseri (nicht operirte Seite). Man sieht grössere und kleinere Formen $(30,60-18,0-14,4 \mu)$. Um den meist central gelegenen Kern findet man einen dunklen Hof, die Zellen sind reich an chromatischer Substanz, mehr disseminirt als concentrisch angeordnet. Einige Zellen sind dunkler gefärbt, besonders in den etwas dickeren Schnitten (nicht genügend differenzirt?), aber normal.

Rechtes Ganglion Gasseri (operirte Seite). Im Allgemeinen fällt der grosse Unterschied zwischen den einzelnen Schnitten auf, indem einige ganz normale Verhältnisse, andere dagegen dentlich degenerirte Zellen darboten. Man begegnet nämlich partieller, Chromatolysis oder stark tingirten, mit undeutlichem Kern, mässig, aber deutlich zusammengeschrumpften Elementen. Bei den ersten ist der Kern wandständig, oft vacuolisirt; man hat manchmal den Eindruck, als ob die gegen einen Pol zusammengeballte chromatische Substanz den Kern mitgerissen hätte. Hie und da, je nach der Schnittführung, dunkle Bruchtheile von Zellen. Die in Chromatolysis begriffenen Zellen zeigen ferner das Tigroid (Thioninfärbung) anstatt violett grün gefärbt.

Rechtes Ganglion cervicale sup. Fast alle Zellen besitzen einen lateralisirten Kern, hie und da sind zweikernige Zellen za sehen. Die Elemente sind arm an Chromatin, welches in einigen Elementen an der Peripherie angehäuft erscheint.

Die Ganglienzellen des VIII. Cervical- und I. Brustsegments des Rückenmarks zeigten nichts Abnormes.

Man kann die Hauptergebnisse dieses Experiments folgendermassen resumiren: Bei der Kauterisation der Cornea degeneriren einige Zellen des Ganglion ciliare, aber durchaus nicht in dem Maasse und mit der Intensität, wie bei der Neurectomia optico-ciliaris; auch einige Zellen des Ganglion Gasseri der operirten Seite weisen deutliche Degenerationen auf.

III. Hund C., weiss, klein, von gekreuzter Rasse, mit beiderseitigem Lencoma afficirt.

\section{Juni 1897 Exenteratio bulbi sinistri.}

Es wurden zwei 1 proc. Morphininjectionen und unmittelbar vor der Operation verschiedene 2 proc. Cocaininstillationen und Subconjunctivalinjectionenen vorgenommen. Nachdem die Cornea in Centrum durch einen 
Haken fixirt war, wird durch ein Staphylommesser der obere Theil durchschnitten und durch einen Scheerenschnitt die untere Hälfte weggenommen. Die Linse und ein grosser Theil des Glaskörpers werden entleert, durch einen Gehilfen die zwei scleralen Stümpfe anseinandergehalten, während der Operateur durch einen mit Watte armirten Péan in die Cavität eindringend, den ganzen Inhalt des Bulbus ausräumt. Die Lider wurden zusammengenäht. Keine Reaction.

Nach 12 Tagen Tödtung durch Chloroform. Fixation im 96 proc. Alkohol.

Rechtes Ganglion ciliare (nicht operirte Seite). Man findet, wie es schon erwähnt wurde, grössere und kleinere Zellen. Bei der Durchmusterung aller Präparate merkt man, dass, obwohl von einer Chromatolysis keine Rede ist, doch einige Zellen nicht ganz dem normalen Typus entsprechen. Fie und da sah man den Kern die Peripherie der Zelle austreiben; manchmal war die Zelle, aber noch mehr der Kern vacuolisirt.

Linkes Ganglion ciliare. Keine Zelle normal; die Chromatolyse beherrscht das mikroskopische Bild. Das Chromatin ist entweder vollständig oder theilweise verschwunden, mitunter rareficirt und blass. Einige Zellen boten folgendes Bild: Die Peripherie ist mit gröberen Chromatinschollen versehen, dann kommt ein chromatinfreies, dann ein feines punktförmiges Chromatinband; es folgt ein etwas geschwollener Kern und lateral sitzend das Kernkörperchen. Viele Zellen (meist die kleinen Formen) sind stark dunkel gefärbt, zusammengeschrumpft, ohne deutliche Chromatinschollen. Nicht selten sehien der Nucleolus verkleinert. Im Allgemeinen habe ich den Eindruck gewonnen, dass die Alterationen nicht den hohen Grad erreicht haben wie nach der Neurectomia optico-ciliaris.

Die linken Ciliarnerven zeigten sich nicht alle in demselben Grad degenerirt. Sie wurden nach 24 stündlichem Verweilen im 1 proc. Ueberosmiumsäure gezupft. Einige Fasern waren ihres Myelins absolut beraubt, in anderen fand man das Myelin hie und da als tropfenförmige Reste; einige Fäden waren strohgelb, mit einer feinen schwarzen Körnung wie bei den nach Marchi fixirten Präparaten.

Rechtes Ganglion Gasseri. Normale Verhältnisse; nur hie und da einige dunkelgefärbte Zellen mit undeutlichem Kern.

Linkes Ganglion Gasseri. Im Grossen und Ganzen normaler Befund; hie und da einige Zellen mit wandständigem Kern, einige dunkel gefärbt, mit etwas undentlichem Nucleus.

Centralregion des Oculomotorius. Das Stück wurde nach Fixirung: in 96 proc. Alkohol in Paraffin eingebettet und in Serien zerlegt. Ich konnte keine Degeneration finden. Man sah einige etwas dunkel gefärbte Zellen, besonders unter den kleinen Elementen sowohl des Oculomotoriuskerns als des Centralgraues vom Anfang des Aquaeductus bis zum dritten Ventrikel.

Der Befund lantet also: Nach Exenteratio bulbi sind die Ciliarnerven und das Ciliarganglion hochgradig degenerirt. Ich fand keine Degeneration im Oculomotoriuskern, ferner keine im Ganglion Gasseri, was als ein schroffer Gegensatz zu dem Befund beim Hund B imponirt. Ich wäre geneigt die verdächtigen Befunde im Ganglion ciliare auf der Seite der am meisten leukomatösen Cornea (nicht operirte Seite) mit dem Leukom in Verbindung zu setzen, allein mit Sicherheit kann ich es nicht behaupten, 
denn Anomalien, welche fast ausschliesslich die Kerne betreffen, können auch technische oder anderweitige Ursachen haben.

IV. Hund D, braun, Weibchen, mittlere Grösse.

Am 26. Juli 1897 wurde nach der schon geschilderten Methode die Neurectomia optico-ciliaris links vorgenommen (Dr. Cofler).

Keratitis neuroparalytica.

Zwölf Tage nach der Operation wurde das Thier durch Chloroform getödtet. Die zwei Opticusstümpfe waren 1-2 $\mathrm{mm}$ auseinandergerückt, und die Ciliarnerven vollständig getrennt. Alle Stücke wurden in 96 proc. Alkohol fixirt.

Rechtes Ganglion ciliare (nicht operirte Seite). Die Zellen im Vergleich mit jenen bei Hond A etwas geschrumpft (Fixationsmethode?). Tigroid, Kern normal:

Linkes Ganglion ciliare (operirte Seite). Vollständige Degeneration der Zellen wie beim Hund A; wenige Elemente ausgenommen, war das Tigroid überall verschwunden, einige Zellen zu dunklen, zusammengeschrumpften, missgestalteten Klumpen reducirt, bei welchen der Kern so verschwommen, dass nur der Nucleolus irgendwo in der Zelle als ein dunklerer Punkt zu treffen war. Bei den in Chromatolyse sich befindenden Elementen sah man den Kern ganz an der Peripherie gelagert oder halb herausgetreten, einige Zellen schienen offen zu sein und ohne Kern, einen sicher in das umgebende Gewebe ausgewanderten Kern konnte man nicht nachweisen.

Linke Ciliarnerven (1 proc. Ueberosmiumsäure, Zupfpräparate) vollständig degenerirt.

Linker $0 \mathrm{culomotorius} \mathrm{(1} \mathrm{proc.} \mathrm{Ueberosmiumsänre,} \mathrm{Zupfpräparat)}$ normal.

Centralregion des Oculomotorius. Identischer Befund wie beim Hund A: normale Ganglienzellen, einige hie und da, am meisten im Centralgrau ausserhalb des Oculamotoriuskerns, mehr dunkel gefärbt. An dickeren Schnitten sind diese Art von Zellen öfter zu finden.

Rechtes Ganglion Gasseri (nicht operirte Seite). Normale Bilder, einige Zellen mit wandständigem Kern.

Linkes Ganglion Gasseri. Man sieht nur in einigen Präparaten gruppenweise Zellen, welche wirklich degenerirt sind, nämlich dunkle, zusammengeschrumpfte Gebilde oder Elemente mit peripherer chromatolyse, in welchen die Chromatinschollen ganz anf einen Theil der Zelle angehäuft erscheinen; der Kern, nach derselben Seite fast hingezogen, buchtete die Zellenwand aus.

Rechtes oberes Ganglion cervicale. Die meisten Zellen sind sehr arm an Chromatin, welches meistens die periphere Zone einnimmt und einen zweiten blassen Ring um den fast immer wandständigen Kern bildet. Einige dunkel gefärbte Elemente sind wohl hie und da zu sehen.

Linkes oberes Ganglion cervicale. Viele Zellen zeigen keine chromatische Substanz, nicht einmal an der Peripherie. Manchmal nimmt der Kern eine ungleichmässige dunkle Farbe an, als ob das Chromatin ganz im Kern gelagert wäre. Der Kern selbst zeigt sehr oft keine ovoide Form, sondern unregelmässige Contouren, nahm manchmal fast die ganze Zelle ein (vacuolisirt?), hie und da war er aus dem Element halb ausgetreten: 
Die beiderseitigen VIII. Cervical-und I. Brustganglien zeigten kein e Anomalie. Viele Zellen mit wandständigem Kern.

Die unteren Cervical- und oberen Brustmarkregionen waren, was die Ganglienzellen ond die Nervenfasern anbelangt, normal.

Zusammenfassend finden wir nach vorgenommener Neurectomia optico-ciliaris vollständige Degeneration der Ciliarnerven und des Ciliarganglions, Degeneration einiger Zellenhaufen des entsprechenden Ganglion Gasseri und vielleicht einiger Zellen des oberen G. sympathicum. Keine Degeneration weder des Oculomotorius, noch der Centralregion desselben, noch jener Spinalganglien und Rückenmarkssegmente, welche mit der Iriserweiterung in Beziehung stehen.

Aus allen diesen Ergebnissen folgt, dass bei Hunden die Exenteratio bulbi und die Neurectomia optico-ciliaris eine vollständige Degeneration des Ciliarganglion zur Folge baben, dass nach diesen 0 perationen abereineDegeneration derZellen im Kern des Oculomotorius meinerAnsicht nach nicht eintritt. Man hat ferner beobachtet, dass nicht in allen, aber doch in einigen Fällen ein Zusammenhang $z$ w is chen Ciliarnerven und Ganglion Gasseri existirt, denn es war sicher eine leichte Degeneration einiger Zellen vorhanden. Wahrscheinlich degeneriren bei den in der Art operirten Thieren auch einige Elemente des Gangl. cervicale sup., ich kann es aber nicht mit Sicherheit behaupten, weil ich nur einmal das Organ beiderseits untersucht habe. Einige Zellen des Ciliarganglions zeigten eine leichte Degeneration beiKauterisation der Cornea; ob das Leukom dieselbe Wirkung auf die Ganglienzellen ausübt, wage ich nicht mit Sicherheit anzunehmen. Entartung der Ciliarnerven war in Folge der Exenteratio bulbi und der Neurectomia optico-ciliaris constant zu finden. Die Spinalganglien und die Rückenmarkssegmente (VIII. Cervical- und I. Brustmark) zeigten keine Anomalie.

\section{Experimente an Affen.}

Im Folgenden werde ich trachten, eine kurze Uebersicht der mikreskopischen normalen Bilder der bei Affen (A maduas) untersuchten Organe zu geben. Die Präparate sind theils einem nicht operirten, theils einem operirten Affen entnommen, jedoch bei letzterem nur auf der der Operation nicht entsprechenden Seite. Dadurch wird ein für alle Male ein fester Boden zur Vergleichung mit pathologischen Bildern gewonnen.

Es handelt sich um Organe, welche mit 96 proc. Alkohol, concentrirter Sublimatlösung und mit meiner Fixationsflüssigkeit behandelt wurden. Bei dieser Vergleichsstudie konnte ich mich wieder einmal von dem grossen Werth dieser letzten Fixationsmethode überzeugen, die Structur der Zelle 
ist dabei sehr gut erhalten, ebenso sind die Nervenfasern, selbst nach Paraffineinbettung, durch die modificirte Weigert'sche Procedur sehr gut zu sehen.

Im Allgemeinen muss ich bemerken, dass die Nissl'sche Methode und ihre Modificationen (Thionin, Toluidenblau) so heiklich sind, dass die dadurch entstandenen Bilder nur mit grosser Vorsicht zu denten sind. Nach einer Reihe von Experimenten, die ich vorgenommen habe, sind ein Zuviel oder Zuwenig der Dicke, der Färbung, der Entfärbung, der Vertrocknung der Präparate, ein zuviel erwärmtes Paraffin ebenso viele Ursachen für's Auftreten von Bildern, die alle möglichen Anomalien der Zelle vortäuschen können. So wurden z. B. die Präparate eines Affen, welcher nach einer missglückten Neurectomie von Irideremie operirt wurde, unbrauchbar, weil das Paraffin bis zu $65^{\circ}$ erwärmt war: alle Zellen waren geschrumpft, stark dunkel gefärbt, der Kern verschwommen und fast immer wandständig. Es ist ferner wichtig, hervorzuheben (Nissl hat anch in der letzten Zeit diesen Punkt ebenfalls betont), dass jedes Organ eine eigene Färbbarkeit besitzt: Chromophilie, Pykno-, Apyknomorphie. Andererseits zeigen geschrumpfte Zellen (Fixationsmethode?) immer eine tiefere Färbung, ebenso können zu feine Schnitte chromatinarme Zellen vortäuschen; bekannt ist ferner die verderbliche Wirkung einer zu starken Austrocknung mit Fliesspapier. Ich muss endlich auf einen sehr wichtigen Punkt aufmerksam machen: man findet manchmal, wie ganz richtig Lugaro hervorgehoben hat, am Rand oder neben dem Rande des Präparats Zellen, welche eine sonderbare Vertheilung des Chromatins zeigen; es scheint, als ob die chromatische .Substanz ganz auf einen Pol gehäuft und die übrigen Zellen derselben fast beraubt wären. Ich habe diese Vertheilung des Chromatins ,à coup de vent" genannt, denn man gewinnt den Eindruck, als ob durch einen Windstoss diese Anhäufung bedingt wäre. Diesen Bildern begegnet man am Rande des Präparats auch bei ganz normalen Gebilden; wenn sie aber an anderen Stellen und mit anderen Alterationen zu finden sind, so darf man denselben eine pathologische Bedeutung zumuthen. Alle diese Momente müssen bei der Beurtheilung jedes Schnittes beriicksichtigt werden.

Die Anatomie des Ganglion ciliare bei dem Affen ist der des Menschen sehr ähnlich, deswegen werde ich nur ein paar Punkte hervorheben. Ein Unterschied liegt darin, dass das Ganglion bei den Affen fast immer mit dem Nerv für den Obliquus inf. scheinbar verwachsen ist, während beim Menschen eirue ausgesprochene Radix brevis makroskopisch zu sehen ist. Die Radix brevis existirt eigentlich anch bei den Affen, sie ist aber nur unter dem Mikroskop sichtbar, und im Widerspruch zu Bernheimer habe ich gefunden, dass Faserzüge aus dem genannten Nerv in das Ganglion selbst baumartig eintreten und sich vertheilen, um wieder durch die Ciliarnerven aus dem Ganglion herauszutreten. Es existirt eine zweite, nicht constante Verbindung zwischen Oculomotoriusstamm und Ganglion, sie ist durch eine feine Wurzel gegeben, welche aus dem oberen (hinteren) Rand (die Stelle ist unbeständig) des Ganglion zum Oculomotorius und zwar neben der Stelle, wo der R. f. den Obl. entspringt, hinzieht. Ich bin nicht sicher, ob auch Fasern aus den Ciliares longi sich hinzugesellen, um weiter zu ziehen, ebensowenig konnte ich dieselben bis ins Ganglion Gasseri verfolgen.

Die Nervi ciliares sind den des Menschen gleich, ich kann also mit 
Hahn( $\left.{ }^{15}\right)$ zwei Arten von Fasern: die dicken mit einer starken, und die feinen mit einer dünneren Markscheide versehenen Bündel, unterscheiden. Wahre Remak'sche Fasern wie im Sympathicus konnte ich nicht beobachten. Im Laufe der Ciliarnerven, besonders in ihrem Anfangsstïck, sind einige Ganglienzellen zwischen den Nervenfasern eingenistet; 4-5 Zellen sind auch im Nervus für den Obliquus in aufsteigender Richtung zu sehen.

Die mikroskopischen Bilder des Ganglion ciliare zeigen, von Mittelformen abgesehen, zwei Grundtypen von Ganglienzellen: die meisten (I. Typus) sind rundlich, 48,8 bis $50,8 \mu$ gross, die Minderzahl (II. Typus) ovoid, 20, 22, $19 \mu$ gross. Das Tigroid der Zellen der ersten Kategorie ist ans feinen und gröberen, concentrisch gerichteten Chromatinkörnern gegebildet, welche sich gegen die Peripherie lichten und einen feinen chromatinfreien Saum zurücklassen, der sich mit der Kapsel vermischt. Die Chromatinkörner hören um den Kern herum auf, einen zweiten Saum bildend. Der Nucleus ist ziemlich gross, hell. Durch basische Farben sieht man oft sehr feine Radien den Kern durchziehen, während durch die Ehrlich'sche oder v. Gieson'sche Methode der Kern von deutlichen Körnern besät erscheint. Der Nucleus liegt meistens central, manchmal etwas excentrisch, er reicht aber nie bis zur Peripherie, das Kernkörperchen ist meist central gelagert.

Bei den Zellen der zweiten Kategorie ist das Chromatin fein und unregelmässig zertheilt, manchmal ist es mehr am peripheren, manchmal mehr am centralen Saum stärker angehäuft. Der Kern ist fast immer etwas excentrisch. Zwischen diesen beiden Typen giebt es zahlreiche Zwischenformen: man findet Zellen, welche $30-20 \mu$ gross sind, mit an der Peripherie concentrisch gegen das Centrum zu ganz unregelmässig geordnetem Chromatin, mit seitlich gerichtetem Kern und Kernkörperchen. Man findet in sehr feinen Schnitten Tigroidreste, d. h. eine Insel wie ein Plättchen von Chromatinkörnern, wahrscheinlich als Theile einer Zelle, welche in einem anderen Schnitt ihren Abschluss findet. Ich kann diese Formen, wenn sie nicht zahlreich sind, an und für sich nicht als patholologisch ansehen. Sehr oft findet man am Rand des Schnittes die Orientirung „à coup de vent". Von seltenen Befunden werde ich folgende erwähnen: Manchmal bemerkt man eine kleine Anhäufung von kleinen, rund-länglichen Zellen, welche offenbar als Kapselreste zu betrachten sind; hie und da konnte man bei Hämatoxylinfärbung eine Art Vorsprung sehen, vielleicht eine Andeutung eines Protoplasmafortsatzes. In Präparaten durch Hämatoxylin-Delafield und durch die v. Gieson'sche Methode gefärbt, erscheint das intercellulare Bindegewebe maschenförmig, mit ziemlich viel Kernen. Ich kann mich nicht aussprechen, ob das Gewebe sich mebr dem Typus des Sympathicus oder der Spinalganglien nähert. Was die Nervenfasern anbelangt, so have ich schon die baumförmige Zertheilung der Radix brevis angedentet, hier sei nur noch erwähnt, dass man den Eindruck gewinnt, als ob ein Theil der Fasern sich zwischen den Zellen, ihre Markscheide verlierend, ausbreiten und dann convergirend als markhaltige Fasern durch die Ciliarnerven austreten. Gefässe im Ganglion selbst habe ich nicht gefunden.

Das Ganglion Gasseri hat im Kleinen eine ähnliche grob-anatomische Structur wie beim Menschen. Mikroskopisch sieht man zwei Arten von Zellen wie beim Ganglion ciliare, von 52,5 bis $25,5 \mu$ und viele 
Mittelformen. Die Zellen des ersten Typus sind denjenigen des Ganglion ciliare ähnlich, nur ist das Chromatin unregelmässig zerstäubt und erreicht die Kapsel. Der Kern liegt meist central oder etwas excentrisch und ebenso der Nucleolus. Die zweite Form ist ovoid oder unregelmässig länglich; sie besitzen einen peripheren und einen um den Kern centralen, aus feinem Chromatin gebildeten Saum, beide sind durch ein chromatinarmes Band getrennt. Der Kern ist fast immer wandständig, durch feines Chromatin unregelmässig ausgesät, welches das Kernkörperchen frei lässt. Die Grundsubstanz der Zelle, mit der Methode von Lugaro studirt, gab mir sowohl bei meiner als bei Alkohol- und Sublimathärtung kein sehr deutliches fibrilläres Bild (Immers.). Es giebt pykno- und apyknomorphe Zellen unter einander vermischt; die Randzellen zeigen oft die Anordnung des Chromatins, à coup de vent". Das Bindegewebe ist reich an Kernen. Die massenhafien Nervenfasern durchziehen bündelweise das Ganglion, einzelne kann man durch das Organ vom Ein- bis zum Austritt, andere dagegen nur bis zur Năhe der Zellkapsel verfolgen. Die Ganglienzellen sind gewöhnlich reihenförmig durch die Länge des Ganglions angeordnet, einige Gruppen liegen auch inselförmig zwischen den Nerven und den Bindegewebsfasern.

Das Ganglion cervicale sup. ist ein etwa $2 \mathrm{~cm}$ langes spindelförmiges Gebilde, dessen Nervenzellen 21,6 $\mu$ lang, $18 \mu$ breit, einige 25,2 $\mu$ lang, 21,6 $\mu$ breit, also ovoid sind; der Kern ist fast immer wandständig. Die Nervenzellen sind chromatinarm, einige Körner bilden den Rand derselben, und eine feine Körnung von chromatischer Substanz umgiebt den Kern, hie und da glaubte ich eine Andeutung der Wurzel eines Protoplasmafortsatzes, immer an der dem Kern gegenüberstehenden Seite zu sehen. Individuell verschieden (Alter?) ist die Pigmentation der Zellen. Der Kern selbst enthält sehr feines und sehr spärliches Chromatin, das Kernkörperchen liegt meistens lateral. Einige Zellon zeigten zwei Kerne. Verschiedenheiten kommen natürlich vor, so findet man z. B. chromatinreiche nnd -ärmere Zellen. Gespaltene Zellen mit zwei Kernen (Marinesco(16)) habe ich nie getroffen. Das Bindegewebe ist mächtig entwickelt, es scheint mir aber nicht kernreich zu sein. Fasern mit deutlicher Myelinscheide konnte ich bei Längsschnitten nicht erkennen, wohl aber Remak'sche Fasern.

Das Ganglion cervicale medium, ein nicht constantes Gebilde, verhält sich histologisch dem vorher beschriebenen gleich.

Das Ganglion sympathicum inferius (thoracicum) ist sehr klein (1-2 mm), knopfförmig, enthält 13,8-20-30 $\mu$ grosse, vielleicht chromatinreichere. Zellen, welche selten zwei Kerne enthalten; gespaltene Zellen konnte ich auch da nie beobachten. Die zwei Kerne sind von chromatischer Substanz getrennt. Die Kerne sind meist wandständig, es giebt aber viele Formen mit central sitzendem Kern.

Das Ganglion jugulare n. vagi. Die Ganglienzellen sind 48,7 bis $18,4 \mu$ gross, so dass die zwei Typen sehr auffallend sind. Die grösseren Formen haben ganz den spinalen. Typus, das Chromatin ist concentrisch gerichtet, mit feinen und gröberen Körnern besät; der Kern ist central, das Kernkörperchen etwas seitlich orientirt. Die kleineren Zellen haben mehr den Typus der sympathischen Elemente; sie haben eine ovoide Form, 
zeigen zwei Ringe von Chromatin, den einen als peripheren, den anderen als perinucleären Saum; zwischen beiden ist die Zelle chromatinarm. Der Kern ist immer wandständig, das Kernkörperchen liegt nicht immer central. Es giebt jedoch eine Menge Zwischenstnfen: grosse Zellen mit wandständigem Kern, 25-30 $\mu$ grosse, mehr oder weniger chromatinreiche Zellen, in welchen die chromatische Substanz entweder unregelmässig gelagert ist oder eine periphere und eine centrale Verdichtung zeigt. Die Nervenfasern sind markhaltig, theil das Ganglion durchziehend, theils mit den Zellen in Verbindung tretend. Das Bindegewebe zeigt dieselbe Structur wie bei den Spinalganglien.

Die Spinalganglien enthalten rundliche Ganglienzellen von drei verschiedenen Hauptgrössen: 57,5-32,2-18,4 $\mu$. Bei den grösseren Formen sind die feinen und gröberen Chromatinschollen concentrisch um den Kern gelagert, der periphere Saum der Zelle ist chromatinfrei, manchmal aber zeigt sich gerade der periphere Saum chromatinreich. Der Kern sitzt in der Mitte, so wie das Kernkörperchen, und ist mit feinem und gröberem acidofilen Chromatin besäet. Die mittleren und kleinen Formen fallen gleich durch den wandständigen Kern auf, das Chromatin ist dabei unregelmässig gelagert, die Körner desselben sind lichter und blässer, das Kernkörperchen liegt lateral. Es giebt jedoch eine grosse Zahl von Mischformen. Was das birdegewebige Gerüst anbelangt, so konnte ich in seiner Structur kein Unterscheidungsmerkmal zwischen den verschiedenen hier studirten Ganglien, das Ganglion symp. und ciliare ausgenommen, finden; bei letzterem kann man nicht mit Sicherheit einen Typus bindegewebigen Gerüstes bestimmen. Bündel von Nervenfasern scheinen einfach das Ganglion zu durchziehen, andere als nackte Axencylinder reichen bis fast zur Kapsel der Ganglienzellen.

Die Centralregion des Oculomotorins. Noch bevor man auf den Kern des Oculomotorius stösst, sieht man das centrale Grau besonders am Boden des Aquaeductus sehr reich an Py-Zellen, welche 20,7 bis $13,8 \mu$ gross sind. Gerade in dieser Region findet man sehr oft, besonders wenn der Schnitt nicht sehr fein gelungen oder wenig entfärbt ist, aber auch in den besten Schnitten, Formen, welche an jene, welche Bernheimer als degenerirte Zellen bezeichnet hat, erinnern und von ihm in dem vermutheten paarigen Centrum für die Pupille gefunden wurden. Es sind Elemente, welche entweder die Py-Formen behalten oder etwas geballt, stark dunkel aussehen, bei welchen der Kern sehr verschwommen, hie und da sogar unkenntlich, oft wandständig ist. Die Fortsätze sind manchmal kurz, sogar etwas korkzieherartig (pathologisch?). Diese Formen kann man nicht gar so selten im centralen Grau der ganzen Prä-, Post- und Oculomotorinsregion finden, also bevor man den Trochleariskern erreicht, und in der Gegend des 3. Ventrikels. Die normalen Formen sind selbstverständlich bei weitem die häufigsten. Einige Zellen des Centralgraues scheinen sich fast zu Gruppen zu verdichten, um zwei Kerne (auf jeder Seite einen) schon im distalen Theil des Oculomotoriuskerns, gegen den Aqueductus zu, zu bilden. Diesen Kernen gehören Zellen von $13,8 \mu, 20,7 \mu$, ja $34,5 \mu$ Grösse an, sie sind dünn, schlank, $9,2 \mu$ breit, mit $4-5$ Fortsätzen, oder rundlich mit 1-2 Fortsätzen. . Weiter proximalwärts beginnen die paarigen, kleinzelligen Kerne von Bernheimer, welche Zellen den kleineren Typus besitzen. Im Oculomotoriuskern sind $20-30 \mu$, hie und da auch 13 bis 
Das Neuron des Ganglion ciliare u. die Centra der Pupillenbewegungen. 379

$12 \mu$ grosse Zellen vorhanden (nicht vollständig getroffene Zellen?). Die Elemente sind sehr schön, so wie die Py-Zellen aller motorisehen Kerne und der vorderen Rückenmarkskörner, ausgebildet, mit vollständig entwickeltem Tigroid. Hie und da, aber selten, findet man jedoch Zellen, die jenen gleichen, welche bei der Besprechung des Centralgraues beschrieben worden sind.

Die Beschreibung des Oculomotoriuskerns, wie sie Bernheimer gegeben, kann ich durchaus bestätigen; der unpaarige, grosszellige Mediankern ist nicht gut abgrenzbar, und geht derselbe in die laterale Zellengruppe über.

Tch habe zum Vergleich Serienschnitte des ganzen Stammhirns, der Oblongata und eines Theils des Rückenmarks vorgenommen and bin nunmehr überzeugt, dass die beschriebenen Schwankungen in der Form und Färbbarkeit der Zellen mehr oder weniger überall zu treffen sind. Dieselben hängen theils von der Schnittführung, theils von der Dicke des Schnittes und von dem Grad der Entfärbung ab. Auch das Erwärmen der Präparate bis zur Blasenbildung hat einigen Einfluss darauf, darum lasse ich jetzt die Schnitte bei Zimmertemperatur 24 Stunden in der Fluissigkeit. Schliesslich ist die Natur der Zellen dabei bestimmend, da bekanntlich gewisse Zellengruppen die Farbflüssigkeit stärker aufnehmen. Dass diese Zellen als nicht normal anzusehen seien, kann man für einige Formen zugeben, jedoch mit dem Bemerken, dass sie von der experimentellen Läsion gar nicht getroffen zu sein brauchen, denn man findet sie anch weit weg von dem vermutheten Centrum, allüberall unregelmässig zertheilt, wie später noch erwähnt werden wird.

Ein Versuch, beide Augen am selben Tage zu operiren, misslang, das Thier wurde nach beiden Operationen cyanotisch, verweigerte das Futter, wurde auch soporös und starb nach zwei Tagen. Die 48 Stunden nach dem Eingriff gefundenen Veränderungen waren aber recht interessant, wie ans Folgendem zu ersehen:

Versuch I. Affe A. Irideremie rechts, Kanterisation der Cornea links.

24. September 1897. Junges, gesundes Thier. Um eine spastische Contraction des Sphincters zu erzielen, wurde einige Male eine 1/2 proc. Eserinlösung rechts eingeträufelt, zur Anästhesie 4 proc. Cocainlösung. Nachdem die Lider mit dem Elevator fixirt worden, wurde der Bulburs mit einer Pincette festgehalten und die rechte Cornea am oberen temporalen Rand incidirt, die Iris wurde mit der Irispincette gefasst und ans der Wunde herausgezogen. Mit einer zweiten Pincette konnte die Iris nahe der Wunde sicher gefasst und vom Ligamentum pectinatum in ihrer Totalität abgelöst werden.

Am linken Auge wurden nach Cocainisation die Lider auseinandergehalten, der Bulbus fixirt und mit einem flachen Cauterium die ganze Cornealfläche tief kanterisirt (Dr. Cofler).

Tod nach 48 Stunden, Die Organe wurden eine Stunde nach dem Exitus herauspräparirt und in meiner Flüssigkeit fixirt.

Linkes Ganglion ciliare (Thionin). Das Chromatin einiger Randzellen ist ,à coup de vent" orientirt. Hie und da einige Zellen mit partioller Chromatolysis. Kern normal. 
Rechtes Ganglion ciliare (Thionin). Man gewinnt den Eindruck, als ob die Zellen schwer in ihren Kapseln Platz finden, die Endothelien der Kapsel dringen, so möchte ich sagen, in die Zelle hinein; die Zellen zeigen eine Art Schwellung, dabei zeigen einige Elemente eine deutliche Chromatolysis. Kerne normal.

Die sympathischen oberen und unteren Ganglien, beide Ganglia Gasseri, einige Spinalganglia normal; bei den letzten sind einige Zellen vielleicht etwas blässer, als es gewöhnlich der Fall ist.

Die centrale Region des Oculomotorius ist normal, hie und da findet man aber sowohl im Centralgrau als im Hauptkern als in den Zellen, welche in dem hinteren Längsbündel liegen, sowohl sehr stark tingirte mit undeutlichem Kern, als in partieller Chromatolysis befindliche Elemente (Thionin, Toluiden-Methylenblau). Vielleicht steht dieser Befund mit dem zum Tod führenden allgemeinen Zustand im Zusammenhang. Das Thier war nicht tuberculös.

Achtundvierzig Stunden nach der Operation fand man also schon die ersten Zeichen einer traumatischen Reaction, während bei einem anderen irideremirten Affen (D), welcher nach 24 Stunden gestorben ist, nichts Abnormes vorhanden war. Die leichte Chromatolysis einiger Zellen sowohl im G. ciliare, als in der Oculomotoriusregion ist meiner Ansicht nach noch kein zwingender Beweis für die anfängliche Reaction, wohl aber die dentliche Schwellung der Elemente des rechten G. ciliare, welche höchst wahrscheinlich als das erste Zeichen der später eintretenden Veränderungen zu deuten ist.

Versuch Ir. Affe B. Nach der angegebenen Methode wurde am 11. October 1897 die Kauterisation der rechten Cornea vorgenommen (Dr. Cofler).

Nach elf Tagen Tödtung durch Chloroform. Fixation nach meiner Methode.

Linkes G. ciliare. Die Zellen sind ganz normal. Nach Durchmusterung aller Präparate konnte ich nur zwei Zellen finden, welche eine partielle Chromatolysis zeigten. Mit der Weigert'schen Methode ganz normale Fasern.

Rechtes G. ciliare. Die grösste Mehrzahl der Zellen ist normal, in einigen Präparaten kaum 2-3 in Degeneration begriffene Zellen, in anderen ist eine grössere Zahl von alterirten Elementen vorhanden. Die Hauptveränderung besteht in einer deutlichen, aber nicht hochgradigen Chromatolysis. Man sieht einige Variationen in den chromatolytischen Zellen, so z. B. einen lichten Fleck, welcher einen Theil der Zelle einnimmt, oder es erscheint die Zelle länglich, mit feinen Chromatinspangen und zwischen den einzelnen Spangen deutliche Chromatolysis. Gewöhnlich ist die Chromatolysis ringförmig und nur um den Kern häuft sich etwas Chromatin; hie und da sind die Grenzen zwischen Kern und Zelle wegen der Blässe der letzteren, oder weil die chromatische Substanz den Kern einnimmt, sehr verschwommen. Kern normal, hie und da ovoider Form.

Rechte Ciliarnerven (1 proc. Ueberosmiumsäurelösung, Zupfpräparate) normal. Hie und da merkt man sehr kurze Unterbrechungen der Myelinscheide (nicht pathognomonisch), keine Myelintropfen, keine myelinlosen Fasern. 
Das Neuron des Ganglion ciliare u. die Centra der Pupillenbewegungen. 381

Linkes Ganglion Gasseri normal.

Rechtes Ganglion Gasseri. Die grosse Mehrzahl der Zellen ist normal. Einige Elemente zeigen aber deutliche Chromatolyse; bei den grossen Zellen ist dieselbe eine periphere, bei den kleinen sieht man eine Art centraler Chromatolyse; es ist nämlich der periphere chromatische Ring vorhanden, der Zellkörper sieht aber sehr blass aus und das Chromatin ist ungewöhnlich fein. Der Kern ist normal. Die alterirten Zellen sind in den verschiedenen Regionen des Ganglions zerstrent, hie und da zu 5-6 gruppirt. Nervenfasern normal.

Linkes und rechtes G. cervicale sup. und inf. normal; viele pigmentirte Zellen.

Centralregion des Oculomotorius normal. Im Centralgrau in den Bernheimer'schen paarigen Kernen, sowie hie und da in beiden Hauptkernen begegnet man den geschilderten dunkeln, manchmal geballten Zellen.

Nach Kanterisation der Cornea findet man also eine qualitativ und quantitativ mässige Degeneration des Ganglion ciliare und einiger Elemente des Ganglion Gasseri auf der operirten Seite.

Versuch III. Affe C. Irideremie rechts nach der schon geschilderten Methode (Dr. Cofler).

Tödtung nach elf Tagen. Fixation in 96 proc. Alkohol.

Linkes Ganglion ciliare normal.

Rechtes Ganglion ciliare. Wenige Zellen zeigen eine deutliche Chromatolysis, die Zahl derselben ist etwas grösser als bei der Kauterisation der Cornea. Viele unregelmässige, blasse Chromatinplättchen ohne Kern; ich möchte, wie ich schon bemerkt habe, diesen Befund an und für sich nicht als pathologisch ansehen, die Zahl dieser Gebilde ist aber eine solche, dass er doch als pathologisch imponirt. Kerne normal, einige wandständig.

Rechte Nn.ciliares (24 Stunden in 1 proc. Ueberosmiumsäure) normal.

Beide Ganglia Gasseri und cervic. sup. normal, die letzteren zeigen einige pigmentirte Zellen.

VIII. Cervical- und I. Brustganglion, sowie die betreffenden Rückenmarkssegmente normal.

Centralregion des Oculomotorius normal.

Nach Entfernung der Iris findet man mässige Degeneration in dem betreffenden Ciliarganglion, etwas mehr als nach Kanterisation der Cornea. Weder das G. Gasseri, noch das ober des Sympathicus, noch die Centralregion des Oculomotorius zeigen irgend welche Anomalie.

Versuch IV. Affe G. Irideremie rechts. Es wurde beim Herausziehen der Iris getrachtet, so viel als möglich Ciliarfortsätze mitzureissen (Dr. Cofler).

Tödtung nach 11 Tagen. Fixation in 96 proe. Alkohol.

Linkes Ganglion ciliare normal.

Rechtes Ganglion ciliare. Dieses Ganglion zeigt viel bedeutendere Alterationen als im vorigen Experiment. Die Zahl der degenerirten Zellen erreicht wohl die Hälfte und die Degeneration der Elemente ist eine tiefgreifende. In diesen degenerirten Formen ist die Chromatolyse eine voll- 
ständige mit wandständigem, manchmal die Zellenwand ansbuchtendem Nucleus. Bei anderen Elementen ist das Chromatin auf einen, einen Theil des wandständigen Kerns einnehmenden Fleck reducirt. Wenige Zellen sind zusammengeschrumpft und in eine dunkle Masse verwandelt, bei welcher kein Kern $\mathrm{zu}$ sehen ist, andere zeigen die Orientation des Chromatins a coup de vent. Der Kern selbst ist bei den stark erkrankten Formen verkleinert.

Linkes Ganglion Gasseri. Ausser der schon geschilderten Orientation ,à coup de vent" des Chromatins bei einigen randständigen Elementen nichts Abnormes.

Rechtes G. Gasseri. Die meisten Präparate sind ganz normal, da die partielle stärkere Färbung einiger Randzellen und eine tiefere Färbung einiger anderen Elemente nicht als pathologisch $\mathrm{zu}$ betrachten ist. In einigen Präparaten sind aber deutlich degenerirte Zellen vorhanden. Einige Zellen zeigen eine unzweifelhafte, manchmal die ganze Zelle einnehmende Chromatolyse und den Kern wandständig, andere sind verkrüppelt, dunkelblau verfürbt, bei welchen man den Kern nicht unterscheiden kann. Beide Formen liegen in einem breiten Areal zerstreut.

Linkes Ganglion cervicale sup. normal.

Rechtes G. cervic. sup. Die meisten Schnitte zeigen nichts Abnormes; in drei Präparaten aber beobachtet man 8-10 Zellen, welche in einem hellen Felde sitzen (man kann also von keiner Ueberfärbung sprechen), die in der grossen Mehrzahl dunkel, zusammengeschrumpft und ohne sichtbaren Kern erscheinen; einige dagegen sind absolut farblos, oder besser gesagt, sie zeigen keine Chromatinschollen; dabei buchtet der wandständige Kern die Zellenwand vor.

Die Centralregion des Oculomotorius ist normal. Hie und da sind schon jene geschilderten, stark tingirten, manchmal geballten Zellen ganz unregelmässig zerstreut zu finden.

Die Entfernung einiger Ciliarprocesse bewirkte demach eine stärkere Degeneration des G. ciliare, einiger Zellen des G. Gasseri und höchst wabrscheinlich eine Degeneration einiger Elemente des G. symp. sup. derselben Seite. Die centrale Oculomotoriusregion erwies sich normal.

Versuch V. Affe L. Die Anfgabe war, die Iris und sämmtliche Processi ciliares zu entfernen; das ist nur durch Extraction der Linse gelungen.

11. Mai 1898 Entfernung der Iris, der Linse und der Processi ciliares auf der rechten Seite.

Nach Cocainisation wird die Haut mit der Scheere am temporalen Winkel gespalten, mit einer Pincette der Bulbus an der nasalen Seite ixirt; $7 \mathrm{~mm}$ von der Cornea entfernt wird im horizontalen Durchmesser derselben, an der temporalen Seite mit dem kleinen de Vincentiis'schen Sichelchen die Sclera eingestochen. Mit dem Instrument wird die ganze Vitreushöhle hinter der Linse bis auf die nasale Seite der Sclera, wo die Spitze des Instruments eindringt, durchgestochen und dasselbe mit der Schneide gegen die Chorioidea durch den ganzen unteren Halbkreis durchgezogen. Ist das geschehen, erfolgt von dem Ausgangspunkt aus die Incision des oberen Theils der Chorioidea mit derselben Inclination and Rich- 
tang des Instruments. So zerfällt die Uvea in zwei Theile: der eine besteht ans der Iris, den Processi ciliares und einem Stïck der Chorioidea, der andere aus den übrigen Partien der Sclera. Beim Herausziehen des Sichelchens merkt man einen kleinen Verlust am Glaskörper.

Mit dem Gräf e'schen Messer wird jetzt eine breite Incision auf der oberen Peripherie der Cornea ausgefïhrt, mit einer Irispincette die Iris breit gefasst, von den Proc. ciliares in toto losgerissen und herausgenommen. Da die Krone der Ciliarprocesse damit nicht ganz entfernt wurde, führt man den kleinen Löffel hinter die Linse und entfernt dieselbe in toto ohne Berstung der Kapsel mit den übrigen Ciliarprocessen.

Die Cornea und die Lider werden genäht. Ein Collodiumverband wird vom freigelassenen Thier weggerissen. Die Cornea trübte sich, wurde anästhetisch, behielt aber ihre Form bei (Dr. Cofler).

An diesem Affen wurde drei Tage vor der Tödtung die erste Nicotineinspritzung in die linke Orbita, wie später berichtet wird, vorgenommen. Es wurdo bei dieser Gelegenheit wiederum festgestellt, dass die rechte Cornea trüb und anästhetisch, die Wunde ganz geheilt war.

Das Thier wird 11 Tage nach der Operation geopfert und man fand im linken (injicirten) Auge keine Läsion, nur ein paar punktförmige Hämorrhagien im retrobulbären Gewebe. worden.

Alle untersuchten Organe sind in concentrirter Sublimatlösung fixirt

Das linke G. ciliare ging leider verloren.

Rechtes Ganglion ciliare. In jedem Präparat sieht man spärliche Zellen, welche normal sind, die meisten sind aber stark degenerirt. Es überwiegt die Zahl der zusammengeschrumpften, stark dunkelblau gefärbten Elemente mit schwer oder gar nicht erkennbarem Kern. Stark wandständigen Kern zeigen die in Chromatolyse sich befindenden Zellen; bei diesen scheint es, als ob der Kern ausserhalb des Zellkörpers gewandert wäre; mit der Immersionslinse aber sieht man, dass er noch in der Zelle sitzt. Anch diese Elemente sind entstellt, in die Länge gezogen, und bei einigen sieht man anch mit den stärksten Vergrösserungen keine Granula. Andere Zellen zeigen eine partielle Chromatolysis entweder als Band, indem das ganze Chromatin um den Kern angehäuft ist, oder als spärliche, blasse, unregelmässige oder spangenförmige Granulaanhäufungen. Vacuolenähnliche Bilder waren nicht selten zu sehen. Das Chromatin des Kerns sehr reducirt, das Kernkörperchen war oft nicht zu unterscheiden. Mit der Lugaro'schen Methode konnte ich keine fibrilläre Anordnung der Grundsubstanz beobachten, diese hatte mehr das Aussehen einer unregelmässigen Punktirung.

Rechte Nn. ciliares (24 Stunden in $1 / 2$ proc. Ueberosmiumsäurelösung, Paraffineinbettung, Serienschnitte). Es war befremdend, dass eine stattliche Anzahl von Fasern verhältnissmässig keine tiefe Degeneration zeigte. Viele waren dünn, mit einer nur braun aussehenden Myelinscheide, andere zeigten das Myelin als schwarze Tropfen, bei noch anderen Fasern war kein Myelin mehr zu sehen. Die Zahl der erhaltenen Fasern aber war grösser, als man erwarten konnte.

Linkes G. Gasseri. Obwohl einige Zellen dunkler gefärbt waren und hie und da eine partielle Chromatolysis sich zeigte, kann ich doch nicht die Befunde als pathologisch ansehen. 
Rechtes G. Gasseri. In 20 von 76 Schnitten findet man deutliche pathologische Veränderungen vieler ganz zerstreuter Elemente; einige Zellengruppen enthalten mehr, andere weniger veränderte Elemente. Im Vergleich zu dem anderen Ganglion ist die Zahl der veränderten Zellen bedeutend grösser. Sowohl die in Chromatolysis als die in Schrumpfung sich befindenden Elemente sind sehr zahlreich. Auch die Chromatolyse erreicht hier bei einigen Zellen fast den Höhepunkt, mit Verlust des Kerns. Oft findet man lichte, unregelmässige Chromatinplättchen ohne Kern. Dieser enthält bei den stark degenerirten Formen sehr lichte Granula; das Kernkörperchen ist verkleinert.

Linkes Ganglion cervicale sup. Hie und da findet man (mehr als gewöhnlich) einige dunkle, andere sehr blasse Zellen; eine sichere Chromatolyse, das eigenartige Bild dieses Organs vor dem Auge haltend, konnte ich nicht finden. Einige Zellen zeigen zwei Kerne, ich konnte aber das scheerenförmige Bild der Zellen (Marinesco) nicht finden. Kerne fast constant wandständig.

Rechtes Ganglion cervicale sup. Ich kann nicht mit Sicherheit behaupten, dass ein Unterschied zwischen diesem und dem linken G. existire. Es giebt vielleicht einige missgestaltete, einige in Chromatolyse sich befindende Elemente, vielleicht ist auch die Zahl der zweifelhaften Befunde grösser als links, aber eine sichere pathologische Veränderung, welche mehr rechts als links ausgesprochen sein sollte, konnte ich bei öfter vorgenommenen Controlu'tersuchungen nicht finden.

Rechtes und linkes G. symp. thor. normal; hie und da Zellen mit zwei Kernen.

Linkes G. jugulare n. vagi. Wenige Elemente (grosse Zellen) zeigen eine deutliche Chromatolyse mit wandständigem Kern, einige kleine Zellen sind dunkel und geschrumpft.

Rechtes G. jugulare n. vagi normal. Hie und da eine Zelle mit partieller Chromatolyse oder etwas geschrumpft, viel weniger als links.

Centralregion des Oculomotorius. Es ist interessant zu sehen, wie im Centralgrau am Boden des Aquaeductus, bevor man noch den Trochleariskern erreicht, einige Elemente vorhanden sind, weiche missgestaltet oder dunkel, geballt mit gewundenen kurzen Fortsätzen versehen sind, andere mit so spärlichem, punktförmigen Chromatin, dass man von einer Chromatolysis sprechen darf. Aehnliche Befunde findet man in einigen zerstreuten Zellen im Trochlearis-Oculomotoriuskern nnd in der Nachbarschaft (Zellen im hinteren Längsbündel, in der Raphe). Eine specielle Localisation dieser alterirten Elemente in den Bernheimer'schen Kernen konnte ich nicht con. statiren, im Gegentheil, diese Kerne (speciell der unpaarige) schienen mir viel weniger alterirte Elemente $\mathrm{zu}$ enthalten.

Linkes. VIII. Cervicalganglion, ausgenommen einige sehr blass und einige sehr dunkel aussehende Elemente, normal.

Rechtes VIII. Cervicalganglion. Die Zahl der kleinen und grösseren Zellen, welche Chromatolyse zeigen, lässt keinen Zweifel obwalten, dass es sich um etwas Pathologisches handelt, einige Kerne sind wandständig und ohne deutliche Alterationen.

Dieselben Befunde gaben mir auch andere Cervical- und Brustganglien sowohl der rechten als auch der linken Seite, vielleicht war rechts die Alteration deutlicher. 
Das Neuron des Ganglion ciliare u. die Centra dèr Pupillenbewegungen. 385

Rückenmark vom II. Cervicalsegment bis zur Py-Kreuzung. Hie und da etwas geballte, andere blässere Zellen mit spärlichem Chromatin und wandstä̀ndigem Kern.

Die Deutung dieser Befunde ist in gewisser Beziehung sehr schwer. Was das G. ciliare auf der operirten Seite anbelangt, sind die Veränderungen so tief und verbreitet, dass man trotz des Verlustes des linken G. ciliare sagen kann, dass das Organ in Folge der Operation tief degenerirt war. Eine deutliche, kaum anders als durch die Operation hervorgerufene. Degeneration zahlreicher Elemente zeigte das rechte Ganglion Gasseri, obwohl auch das linke Ganglion nicht ganz normal zu finden war. Bei den Ganglia cervic. sup. dagegen sind die Befunde schon schwer zu erklären. Sind die anormalen Zellen im rechten Organ durch die Operation hervorgerufen worden? Wir haben gesehen, dass kaum ein Unterschied vorhanden war zwischen beiden Ganglien, man kann also das unilaterale Trauma nicht für die zweiseitigen Alterationen verantwortlich machen. Andererseits waren das linke G. jugulare, viele Spinalganglien und einige Theile des Stammhirns und Rückenmarks, was die Ganglienzellen anbelangt, nicht ganz normal. Sind diese Alterationen. durch eine latent verlaufene febrile Krankheit oder durch die Nicotinvergiftung (acute?) oder durch individuelle Verhältnisse entstanden?

Es ist sehr schwer, eine Antwort darauf zu geben, ich werde später diese Frage discutiren müssen. Jetzt sei noch hervorgehoben, dass die Bernheimer'schen. Kerne keine besonders ausgesprochene Alteration zeigten.

Versuch VI. Affe E. Am 7. December 1897 wurde in der schon angegebenen Weise die Exenteratio bulbi dextri vorgenommen (Dr. Cofler).

Tödtung nach 11 Tagen. Fixation in 96 proc. Alkohol.

Linkes Ganglion ciliare. Man findet hie und da einige Chromatinplättchen ohne Kern und fast in jedem Präparate ein paar Zellen, welche periphere Chromatolyse zeigen. Ich habe mir alle Mühe gegeben, um heraus. zufinden, ob dies nicht das Anfangsstïck des Protoplasmafortsatzes wäre: das ist aber gewiss nicht der Fall, denn die. Stelle war wie ein Stück Band halbmondförmig in einer gewissen Strecke in der Zelle zu verfolgen. Einige Zellen mit seitenständigen Kernen.

Das rechte G. ciliare ist leider verloren gegangen.

Rechte Nn. ciliares (24 Stunden in 1 proc. Ueberosmiumsäurelösung, Zupfpräparate). Während die linken normal waren, sieht man bei den rechten Ciliarnerven bedeutende Alterationen. Viele Fasern sind gleichmässig gelb, von einer Myelinscheide ist keine Rede, andere zeigen hie and da einen schwarzen feinen Sand oder schwarze Tröpfchen im Innern der Fasern, welche oft unterbrochen sind. Es giebt jedoch andere Fasern, 
bei welchen eine deutliche Myelinscheide $\mathrm{zu}$ sehen ist, in anderen Fasern erscheint sie graugelb.

Linkes Ganglion Gasseri. Im Grossen und Ganzen normal, in einigen Präparaten sieht man aber Zellen, welche den Verdacht der centralen und peripheren Chromatolysis erwecken. Es sind auch auffallend viele blasse Chromatinplättchen ohne Kern und Kapsel zwischen den gut ansgebildeten Zellen zerstreut.

Im rechten Ganglion Gasseri sieht man in vielen Präparaten ganz unregelmässig vertheilte, degenerirte Zellen, welche meistens eine sehr weitgehende periphere Chromatolyse zeigen; einige Elemente sind missgestaltet, zu stark dunklen Flecken geschrumpft. Der Kern ist sehr oft auch bei den grossen Formen wandständig, das Kernkörperchen stark verkleinert.

Linkes G. cervicale sup. normal; hie und da aber sind einige Zellen für Chromatolysis verdächtig.

Rechtes Ganglion cerv. sup. Viele Zellen sind alterirt. Obwohl man berücksichtigen muss, dass viele Elemente de norma arm an chromatischer Substanz sind, so kann man doch von deutlicher Chromatolyse sprechen. Diese trifft mehr die Peripherie als Fleck oder als gestrecktes 8 $(\infty)$, manchmal 2-3 kleine Vacuolen bildend; wenige Elemente zeigen dagegen eine wahre centrale Chromatolyse. Einige Zellen sind tief gefärbt, zusammengeschrumpft, mit verschwommenem Kern. Ich habe schon bemerkt, dass bei den sympathischen Zellen die Wandständigkeit des Kerns kein pathologisches Zeichen ist, hier waren aber viele Zellen von dem Kern wirklich ausgebuchtet, in anderen Elementen zeigte sich der Kern bei der Ehrlich'schen Fürbung wie ein gleichmässig rother Fleck, in anderen schien der Kerninhalt von spärlichen feinen Körnern besäet, und der Nucleolus war unkennbar. Diese Alterationen fand man sowohl bei den kleinen als bei den grösseren Formen.

Linkes G. symp. thor. normal; vielleicht undeutliche centrale Chromatolyse in einzelnen Elementen.

Rechtes G. symp. thor. Es ist schwer, sich ein bestimmtes Urtheil zu bilden. Es scheint hie und da, dass periphere Chromatolyse vor sich gehe, ferner findet man an einzelnen Punkten Protrusion des Kerns; ich kann aber diese Befunde an und für sich nicht als sicher pathologisch ansehen.

Centralregion des Oculomotorius. Einige Zellen des Centralgraues zeigen sehr deutlich jene tiefe Färbung, die schon erörtert wurde. Daneben sind aber wirklich alterirte Elemente. Man sieht nämlich in jedem Schnitt 3-4 Zellen mit stark wandständigem Kern, auch Protrusion des Zellkörpers auf einer Seite, Anhäufung des Chromatins neben dem Kern und starke Verarmung desselben in der übrigen Zelle. Man sieht nicht mehr die stäbchenförmige Chromatinsubstanz, sondern die ganze Zelle ist entweder durch feines Chromatin zerstäubt oder tief dunkel verfärbt, mit gewundenen, sehr kurzen Fortsätzen; einige Zellen sind wirklich missgestaltet. Der Kern zeigte sich manchmal wie gequollen, andere Male stark verkleinert und das Kernkörperchen unkennbar. Diese Alterationen einiger Zellen des Centralgrau, welche, noch bevor der Trochlearis- und Oculomotoriuskern zu Tage kommen, bemerkbar sind, findet man, obwohl seltener, im Oculomotorinskern sowohl rechts als links unregelmässig im 
ganzen Gebiet und in den Elementen, welche im hinteren Längsbündel und der Raphe sitzen. Eine specielle Anhäufung solcher alterirten Zellen in den Bernheimer'schen Kernen konnte ich bei wiederholten Vergleichsuntersuchungen nicht finden, im Gegentheil, die meisten veränderten Zellen konnte ich mit Sicherheit im Centralgrau beobachten.

Spinalganglien. Die Untersuchung erstreckte sich anf das VIII. Cervical- und I. und II. Brustganglion beiderseits. Die Ganglien der linken Seite zeigten einige veränderte Zellen mit peripherer oder centraler Chromatolysis, und im Kern sah man oft eine feine Zerstäubung des Kernkörperchens. Mehrere Zellen der rechten Seite zeigten deutliche Veränderungen, besonders die des I. Brustganglions. Es waren viele missgestaltete, kleine Formen, andere in totaler Chromatolyse mit Ausbuchtung des Kerns; sehr deutlich war die Lichtung der Kernkörperchen bei der Ehrlichschen Färbung.

Vom VI. Cervical- bis zum III. Brustmarksegment werden Serienschnitte angefertigt. Fast dieselben Verändernngen sind wie im Oculomotoriuskern za finden, nur merkt man anch hier, auch in den Hinterhörnern, dass sie weniger ausgesprochen sind, als in den Zellen des Centralgraues.

Die Ergebnisse dieses Experiments reihen sich an die des vorigen und sind ebenfalls sehr schwer zu erklären. Leider ist das Ciliarganglion auf der operirten Seite verloren gegangen; rom rechten G. Gasseri und oberen Sympathicus kann man wohl annehmen, dass die qualitativ und quantitativ pathologischen Veränderungen wenigstens theilweise dem Experiment zuzuschreiben sind. Alle untersuchten Organe zeigten sich aber mehr oder weniger ergriffen, und in diesem Falle wurden keine Experimente mit Nicotin vorgenommen. Die Fixationsmethode kann auch nicht die Ursache jener Veränderungen sein, im vorigen Experimente wurden die Organe in Sublimat, in diesem in 96 proc. Alkohol fixirt. Technische Fehler kann ich mit ruhigem Gewissen ausschliessen, die Paraffintemperatur wurde strengstens überwacht; ẗbrigens sind nur die Ganglien in Paraffin eingebettet worden. Am wahrscheinlichsten ist noch, dass sowohl dieses als auch das vorherige Thier, obwohl nicht tuberculös, doch krank waren. Entweder wegen dieser schwächenden, mir unbekannten, vielleicht dyskrasischen oder fieberhaften Krankheit haben die Nervenzellen in jener ungewöhnlichen Art bei einer einseitigen Operation reagirt, oder es verursachte die Krankheit selbst die pathologischen Veränderungen in den untersuchten Organen der linken und zum Theil auch der rechten Seite, sowie jene im Centralorgan. Wir wissen aus den Arbeiten von Lugaro (17), Flatau, Goldscheider, Brasch, was für eine deletäre Wirkung auf die Nerven- und Ganglienzellen die Hyperthermie ausübt, und es kann wohl möglich sein, dass beide Affen eine fieberhafte Affection durchgemacht haben, ohne dass wir dieselbe bemerkten. Ein anderer Factor wäre zu berücksichtigen, 
nämlich das Chloroform, welches als Tödtungsmittel angewendet wurde. Wir wissen aber durch Wright, dass Chloroformvergiftungen Chromatolyse hervorrufen können, während hier eine ganze Reihe von Degenerationen gefunden wurden; man muss ferner berücksichtigen, dass andere Thiere, welche auch durch Chloroform getödtet wurden, keine solche Alteration der Zellen in den verschiedenen Gebieten gezeigt haben.

Jedenfalls beweisen diese Befunde, wie vorsichtig die Schlüsse des Experimentators sein müssen und wie leicht Täuschungen vorkommen können.

Versuch VII. Affe J. Am 2. Mai 1898 wurde von Herrn Dr. Cofler nach der schon angegebenen Methode die Exenteratio bulbi dextri vorgenommen. Tödtung nach 11 Tagen. Fixation in 96 proc. Alkohol.

Linkes Ganglion ciliare normal.

Rechtes Ganglion ciliare. Einige Schnitte aus der Kuppe des Ganglions zeigen eine gewisse Zahl von verhältnissmässig gut erhaltenen Zellen, die anderen Elemente sind stark degenerirt, und in den weiteren Schnitten ist es schwer, eine normale Zelle zu finden. Die meisten Elemente zeigen eine sehr ausgebildete Chromatolyse mit theilweiser Anhäufung von Chromatin um Kern. Es sind auch alle anderen Degenerationsformen vorhanden, so z. B. Missbildung der Zellen, welche zusammengeschrumpft, gezackt, dunkel, ohne Kern zu sehen sind; andere Zellen sind glasige Gebilde geworden, man merkt kein Chromatin und keinen Kern; noch andere zeigen eine partielle Chromatolysis und einen wandständig die Zelle ausbuchtenden Kern; wieder bei anderen sieht man einige Chromatinreste, keinen Nucleus unả blos den Nucleolus, welcher, nur weil er von einem lichten Hofe umgeben, von einer Chromatinscholle zu unterscheiden ist. Eine starke Lichtung des Chromatins im Kerne selbst ist in den degenerirten Zellen auffallend. Durch die Hämatoxylinfärbung konnte ich höchstens eine Punktirung der Grundsubstanz erhalten.

Linke Nn. ciliares. (Nach Hahn behandelt. 24 Stunden in $1 / 2$ proc. Osmiumsäure, 24 Stunden in Wasser, Parafineinbettung; die Serienschnitte wurden am Deckgläschen angeheftet.) Es wurden Quer- und Längsschnitte untersucht; an den Querschnitten sieht man sehr deutlich kleinere und grössere Fasern, dickere und feinere Myelinscheiden und mittlere Formen; wahre Remak'sche Fasern sind nicht zu sehen. Alle Fasern waren normal.

Rechte Nn. ciliares (dieselbe Methode). Die meisten Fasern sind degenerirt, einige Bündel mehr, andere weniger. Am häufigsten findet man neben einem vollständig degenerirten Faserbündel (keine Myelinscheide mehr) einige Fasern, welche keine so starke Degeneration aufweisen. Bilder, bei welchen die meisten Fasern normal wären, giebt es nicht. Die Degeneration zeigt keine Vorliebe für dickere oder dünnere Fasern. An den Längsschnitten ist die complete Degeneration durch die lichtgelbe Färbung der Fasern auffallend; die unvollständige giebt sich folgendermaassen kund: Man sieht streckenweise das Myelin in viele, sehr kleine Tropfen zerlegt, meistens schwarz, aber oft von branner Farbe, manchmal findet man die Myelinscheide scheinbar normal, wenn man aber genau bei 
Das Neuron des Ganglion ciliare u, die Centra der Pupillenbewegungen. 389

stärkerer Vergrösserung das Präparat ansieht, so merkt man, dass die charakteristische schwarze Linie aus feinen schwarzen Körnern besteht, das Myelin ist ganz zerbröckelt.

Linkes G. Gasseri normal.

Rechtes G. Gasseri. Die meisten Schnitte zeigen normale Verhältnisse, sechs Schnitte dagegen schwere Alterationen in verschiedenen Zellengruppen. Man sieht einige normale neben einigen in mehr oder weniger, aber immer in deutlicher Chromatolysis sich befindende Elemente, daneben andere dunkel gefärbte, geschrumpfte, ganz missgestaltete Zellen ohne oder mit wandständigem, undentlichem Kern.

Linkes G. cerv. sup. normal, obwohl die Schnitte etwas dick und geschrumpft sind.

Rechtes G. cerv. sup. Auch diese Präparate sind etwas dick und geschrumpft, die Zellen zeigen jedoch zum Unterschied von denen der anderen Seite die schon oft beschriebenen Abweichungen: Chromatolysis, starke Ausbuchtung des Kerns, Schrumpfung und eine fast schwarz aussehende Ueberfärbung der ganzen Zelle. Da aber die Schnitte, wie gesagt, nicht tadellos ausgefallen sind, so würde ich aus diesen Schnitten allein keine Schlüsse ziehen.

Beide Gg. symp. media und thorac. sind normal, zahlreiche pigmentirte Zellen.

Beide Gg. jugul. n. vagi normal.

Rechtes G. spin. cerv. VIII normal; hie und da an der Peripherie einige überfärbte Zellen ohne dentlichen Kern.

Rechtes G. thorac. I normal.

Einige Cervical- und Brustganglien der linken Seite, bei welchen die Temperatur des Paraffins bei der Einbettung plötzlich und anhaltend bis $68^{\circ}$ stieg, gaben ganz unbrauchbare Präparate. Fast alle Zellen waren dunkel und verkleinert, keine Chromatolyse.

Für die Centralregion des Oculomotorius gilt das schon Gesagte, sie war meiner Ansicht nach normal.

Beide Ocnlomotorii (Osmiumsäure, Paraffineinbettung) normal.

Das Rückenmark vom III. Brustsegment bis zur Oblongata normal. Hie und da sind einige Zellen dunkel gefärbt.

Als Resumé kann man sagen, dass in Folge der Exenteratio bulbi starke Degeneration des betreffenden $G$. ciliare, Degeneration einiger Zellengruppen des G. Gasseri und höchstwahrscheinlich des G. symp. sup. auf der operirten Seite eintritt.

Versuch VIII. Affe F. Am 4. Januar 1898 wurde die Neurecto mia opticociliaris dextra vorgenommen.

Durch einen früheren Versuch belehrt, wie leicht es ist, einen vom Oculomotoriusast innervirten Muskel oder die dünne Sclera zu lädiren, wird, um beidem vorzubeugen, wie folgt operirt. Man spaltet die Commissura externa palpebrarum und nach Präparirung des knöchernen Orbitalrandes wird mit einer starken Knochenzange ein Stück Knochen entfernt. Nach Stillung der Blntung incidirt man die Conjunctiva bulbi nahe der Anheftung des M. externus, isolirt den Muskel, trennt seine Sehne von der Sclera 
und nimmt ein Stück des Muskels selbst weg. Mit einer Pincette fasste der Operateur die abgeschnittene Sehne, drehte den Bulbus nasalwärts, und mit einer starken krummen Scheere, welche hinter den Bulbus geführt wurde, schnitt er den Opticus und die Ciliarnerven ab. Mit Compression wird die Blutung gestillt, dann eine Pincette hinter den Bulbus geführt, mit dieser der periphere Opticusstumpf gefasst und sammt dem Bulbus so rotirt, dass man ihn sehen konnte; so war es leicht, auch den peripheren Stumpf mit den Ciliarnerven knapp am Bulbus noch einmal abzuschneiden. Der Bulbus wurde reponirt. Um einen eventuellen Exophthalmus durch Blutung zu vermeiden, wird durch die Conjunctiva- und Hautnaht die resultirende Rima palpebrarum stark verkürzt (Dr. Cofler).

Keratitis neuroparalytica.

Tödtung nach 11 Tagen. Fixation nach meiner Methode.

Linkes Ganglion ciliare normal. Hie und da am Rand des Präparats Zellen mit Orientirung des Chromatins "à coup de vent".

Rechtes Ganglion ciliare. Alle Zellen sind mehr oder weniger intensiv degenerirt. Hie und $\mathrm{da}$ (nur in 2 Präparaten) eine halbwegs erhaltene Zelle mitten im allgemeinen Untergange. Die Chromatolyse ist die verbreitetste Degenerationsform, sie ist fast total, der Kern, entweder kaum mehr zu sehen oder wandständig, buchtet den Rand der Zelle fast zum Durchbruch aus. Eine grosse Zahl von Zellen ist so zusammengeschrumpft, dass man nichts mehr als einen blauschwarzen, 14,4 $\mu$ grossen Fleck vor Augen hat. Einige Kerne zeigen bei der Ehrlich'schen und v. Gieson'schen Färbung eine starke Lichtung des Kernchromatins; man sieht nämlich nur eine unregelmässig zertheilte Zerstäubung von Körnern. An den geschrumpften Zellen ist der Kern in der dunklen Zellenmasse unkennbar. Die Nervenfasern (Weigert-Vassale) normal. Das Bindegewebe zeigte keine Proliferation der Kerne. Bei der Färbung nach Lugaro konnte ich keine deutlichen Bilder bekommen.

Die Reste der rechten Ciliarnerven (Ueberosmiumsäure) waren ganz degenerirt, man sah keine Myelinscheide mehr.

Der rechte N. oculomotorius war normal (Ueberosmium).

Linkes G. Gasseri normal, nur am Rande des Präparates die schon beschriebene Orientation ,à coup de vent".

Rechtes Ganglion Gasseri. Die Mehrzahl der Präparate zeigte normale Verhältnisse, hie und da stark tingirte und etwas geschrumpfte Zellen, hie und da nicht nur wandständige, sondern auch die Wand aus. buchtende Kerne, aber keine dentliche Chromatolyse. In 8 Präparaten stösst man auf einen wichtigen Befund. Bei der Untersuchung jedes einzelnen Schnittes bei schwacher Vergrösserung war ich gleich überrascht, ein circumscriptes Areal mitten im Ganglion zu sehen, in welcbem alle Zellen degenerirt schienen. Das war so befremdend, dass ich meine grösste Aufmerksamkeit darauf richtete. Diese Zellengruppe war von den anderen, in länglichen Reihen angeordneten Gruppen etwas entfernt, inselförmig zwischen den Nerven- und Bindegewebsfasern ungefähr in der Mitte des Ganglion sitzend, in 8 Schnitten dentlich differenzirt, und war von lauter degenerirten Zellen, wie ein degenerirter Kern eines Nerven, gebildet; je nach der Entwicklung dieses Kerns fand man in den Schnittserien 8, 15, 20 und mehr degenerirte Zellen. Einige Elemente zeigten bei stärkerer Vergrösserung eine vollständige Chromatolyse, andere nur partiell, die meisten eine 
Das Neuron des Ganglion ciliare u, die Centra der Pupillenbewegungen. 391

Schrumpfung und Missbildung mit gezackten, unregelmässigen Rändern, bei welchen Zellsubstanz und Kern in einen tief dunkelblauen Klumpen verwandelt waren. Der Kern der in Chromatolysis befindlichen Zellen war wandständig und buchtete oft die Zelle so aus, dass man den Eindruck der Lostrennung hatte, die Immersionslinse zeigte aber, dass der Kern noch in der Zelle lag. Das Kernkörperchen war klein, blass, oft nicht zu finden. $\mathrm{Da}$ diese degenerirte Zellengruppe von der Peripherie des Schnittes entfernt sass und die anderen Gruppen nichts Besonderes darboten, da dieser Befund in allen Schnitten, wo diese Zellengruppe vorhanden, ungefähr der gleiche war, da die minutiöse Vergleichung mit derselben Gruppe des linken Ganglions in diesem ganz normale Verhältnisse ergab, so konnte ich nicht zweifeln, dass wir eine im Zusammenhang mit der Operation stehende circumscripte Läsion einer Zellengruppe vor uns hatten.

Um ganz sicher zu sein, ersuchte ich meinen hochgeschätzten Freund, Prof. Giovanni Mingazzini in Rom, welchem ich hier herzlichst danke, mir darüber sein geschätztes Urtheil mittheilen zu wollen und schickte ihm ein paar Präparate des linken und des rechten G. Gasseri. Er schreibt mir. dass, ,obwohl die Färbung etwas unregelmässig war, so dass die Untersuchung mit der Immersionslinse nicht am besten gelang, obwohl im normalen Präparat hie und da Zellen vorhanden, die eine Concentration des Chromatins anf einen Punkt zeigen (die schon notirte Orientation ,à coup de vent"), man trotzdem sagen darf, dass jene in Frage kommenden verunstalteten, mit Verschwinden des Kerns, des Kernkörperchens und des Chromatins gekennzeichneten Elemente nur als degenerirte Zellen aufzufassen sind".

Linkes G. cerv. sup. normal.

Rechtes G. cerv. sup. Die meisten Zellen normal, es giebt aber sowohl hie und da zerstrente, wie auch gegen die Mitte zu angehäufte Zellen, welche sicher als pathologisch verändert zu deuten sind. Anstatt der gewöhnlichen, etwas blassen Färbung, welche in den sympathischen Zellen de norma vorherrscht, sind die Zellen stark dunkel gefärbt und zusammengeschrumpft, ohne Unterschied von Kern und Kernkörperchen. Der Kern ist dort zu sehen, wo ein halbmondförmiger, lichter Saum nach der Zellensubstanz $z \mathfrak{u}$, den wandständigen Kern begrenzt. Andere Zellen zeigten dagegen einen vollständigen Mangel an Chromatin, sehr oft war der Kern nicht zu finden oder buchtförmig fast aus der Zelle vortretend.

Das G. sympathicum thoracicum beiderseits vollständig normal.

Es wurden verschiedene Spinalganglien untersucht: die VIII. Cervical- und I. und II. Brustganglien der rechten und der linken Seite, und noch andere zur Controle; ich konnte darin nichts Pathologisches entdecken.

Centralregion des Oculomotorins. Ich muss sie als normal in allen ihren Kernen bezeichnen. Auch hier passen die Bemerkungen, die ich bei der Besprechung dieser Region oft wiederholt habe. Alle Schnitte wurden genau untersucht, unter einander verglichen, die verschiedenen Regionen durchmustert, und konnte ich nichts Abnormes finden. Nur in einem Schnitt fand ich in dem unpaarigen Mediankern Bernheimer's drei Zellen, welche dunkel, etwas geballt aussahell, mit etwas undeutlichem Kern und gewundenen kurzen Fortsätzen, ich kann aber nicht von dem Zweifel befreit werden, dass diese Zellen accidentelle Retractionsbilder darstellten, $1 \mathrm{~m}$ so 
mehr, als in dem übrigen Gebilde keine verschiedene Stufe von Degeneration zu sehen war: Chromatolyse u. s. w., und man gleichen Bildern auch in anderen Theilen vereinzelt begegnet.

Ganglion Habenulae beiderseits normal.

Centralregion des Abducens. Bei der ununterbrochenen Schnittreihe fand ich in jedem Schnitt 5-8 Zellen, welche rechts dentlich degenerirt waren; es zeigte sich Chromatolysis mit wandständigem Kern oder Schrumpfung und Dunkelfärbung des gezackten Zellkörpers mit Verschwinden des Kerns. Die Degeneration war so dentlich, dass man bei schwacher Vergrösserung aus dem mikroskopischen Bild diagnosticiren konnte, ob der rechte oder der linke Kern vor uns lag. Tch habe bei der Operation absichtlich ein Stück des Externus excidiren lassen, um bei der Untersuchung des Centrums eine Controle für die Beurtheilung der Oculomotoriusregion zu gewinnen, und in der That zeigte der Vergleich, dass man, meiner Ansicht nach, bei der letzteren nicht von einer Degeneration der Zellen sprechen darf.

Die Wurzeln des Abducens (Weigert-Vassale) zeigen keine Veränderung.

Ich habe auch die Centralregion des Trigeminus in Serienschnitten zerlegt und normal gefunden, sowohl dessen spinale als cerebrale Wurzel.

Von der Oblongata bis zum dritten Brustmarksegment wurden ebenfalls Serienschnitte angefertigt. Es war nichts Pathologisches zu finden. In manchen Schnitten, besonders in den Hypoglossus- und Accessoriuskernen, fand man ein paar dunkelgefärbte, manchmal etwas geschrumpfte oder als dunkle Theile einer Zelle erscheinende Elemente; auch dieser Befund mahnt zur Vorsicht.

Wir haben also hier nach der Neurectomia optico-ciliaris das Prototyp der Degeneration vor uns. Wir fanden eine tiefe Degeneration des Ganglion ciliare in allen Zellen, eine Degeneration im G. Gasseri, welche merkwürdiger Weise sehr tief alle Zellen einer bestimmten Gruppe trifft, ferner Degeneration einiger Elemente des G. cervicale sup., keine des $G$. thorac. Ich habe in der Centralregion des Oculomotorius keine wirklich degenerirten Zellen finden können, ebenso in dem übrigen Stammhirn (Abducenskern ausgenommen) und im Rückenmark. Die Ciliarnerven waren an der operirten Seite degenerirt, der Oculomotorius zeigte ein normales Verhalten.

Es hätte mich zu weit geführt, die Degeneration des Opticus und der betreffenden Centralregionen zu studiren, ich musste dieselbe also ausser Acht lassen, da sie nicht im Rahmen meiner Untersuchungen lag.

Zweck des folgenden Experiments war, zu bestimmen, ob die Nervenfasern im Ganglion ciliare, die Radix brevis, einige Fasern des Nervs für den Obliquus inf. und des Oculomotorius nach Durchschneidung der Ciliarnerven durch die Marchi-Methode degenerirte 
Fasern zeigen, ferner, ob eine Degeneration von Nervenfasern in den betreffenden Spinalganglien und Rückenmarkssegmenten sich einstellen würde.

Versuch IX. Affe M. Am 14. Juni 1898 wird durch die schon besprochene Methode von Herrn Dr. Cofler die Neurectomia opticociliaris dextra mit Extirpation des M. externus vorgenommen. Die starke Hämorrhagie wird durch die vollständige Sutura palp. gestillt.

24 Tage nach der Operation wurde das Thier getödtet. Es zeigte sich, dass die Operation vollständig gelungen war.

$\mathrm{Nn}$. ciliares rechts (24 St. in $1 / 2$ proc. Ueberosmiumsäure, Paraffinschnitte). Es wurde nur der centrale Stumpf des Bündels untersucht. Die meisten Fasern waren vollständig degenerirt, einige jedoch (die nicht neurectomirten?) zeigten eine verhältnissmässig erhaltene Myelinscheide. Einige Fasern wiesen einen schmilen, braun aussehenden, durch schwarze Schollen unterbrochenen Myelinmantel auf.

Rechtes Ganglion ciliare mit dem $Z$ weig für den Obliquus inf. (Marchi). Die meisten austretenden Ciliarnervenfasern zeigen eine dentliche Degeneration. Viele sind nur anf die leeren, streckweise collabirten Scheiden reducirt, in anderen Fasern sieht man Reihen von feinen und gröberen, schwarzen Punkten, welche sich gut von den anderen unregelmässigen, schwarzen Schollen unterscheiden, die in der Umgebung der Fasern in stattlicher Menge $\mathrm{zu}$ sehen sind und welche wahrscheinlich einen pathologischen Zustand verrathen. Diese Schollen sind wieder ganz anders gestaltet, als die hier und da im Innern der Fasern in fast regelmässigen Abständen zu findenden Punkte, welche man schwer anders als Endothelien der Schwann'sehen Scheiden auffassen kann. Die Degeneration des Myelinmantels ist im Ganglion selbst für eine kurze Strecke, nur ausnahmsweise bis in die Năhe der Zellenkapsel zu verfolgen.

Höchst interessant war der Befund der Radix brevis und des N. für den Obliquus inf. sowohl in auf- als in absteigender Richtung: Sowohl die erstereals der letztere zeigten keine pathologischen Erscheinungen. Die Fasern boten die gewöhnliche gelbe Farbe dar; hier und da zwischen denselben einige gelbe Punkte, sonst nichts. Dasselbe Aussehen hatte sowohl der rechte als der linke Ocnlomotorius (Längsschnitte).

Der rechte Abducens (Längsschnitte) zeigt feinkörnigen schwarzen Myelindetritus in fast allen Fasern.

Die Querschnitte des rechten Opticus sind mit schwarzen, in den Fasern selbst liegenden Punkten dicht besäet; die Degeneration nimmt aber centralwärts merklich ab.

Der Vagus und Sympathicus normal.

Keine pathologischen Veränderungen zeigten nach eingehenden vergleichenden Untersuchungen die ebenfalls nach Marchi fixirten VIII. Cervical- und I. und II, Brustganglien sammt ihren ein- und austretenden Wurzeln sowie die betreffenden Rückenmarkssegmente.

Folgende Organe wurden in meiner Flüssigkeit fixirt.

Das linke Ganglion ciliare (Nicotinversuch s. n.). Die grösste Mehrzahl der Zellen ist normal, hier und da einige Formen partieller Chro- 
matolyse (Thionin). Der Kern normal. In dem intercellulären Bindegewebe, in den Nervenfasern nichts Abnormes.

Das linke Ganglion Gasseri normal. Hie und da einige geschrumpfte und dunkel tingirte Zellen, besonders nahe dem Rande des Präparats.

Das rechte Ganglion Gasseri bietet in einigen Schnitten, und ganz besonders in einigen Zellengruppen, dentliche Degeneration der Zellen. Diese sind nicht geschrumpft, sondern in deutlicher Chromatolysis (mit wandständigem Kern) begriffen. Durch den Vergleich mit dem linken Ganglion tritt die Veränderung scharf hervor.

Es wurde beiderseits das Ganglion cervic. sup. mit dem jugulare n. vagi zusammen herausgenommen, fixirt und in Serien zerlegt. Dabei zeigte es sich, dass ein Sporn von sympathischen Zellen ins Ganglion n. vagi hineintrat, und dass diese durch Zwischenstufen allmählich ein dem spinalen Typus sehr ähnliches Aussehen annahmen.

Linkes Ganglion cervic. sup. normal.

Rechtes G. symp. sup. Ich konnte nichts sicher Pathologisches finden. Es giebt einige Formen, welche vielleicht als eine Chromatolyse imponiren könnten, aber bei dem Vergleich mit dem anderen G. schien es mir gerathen, diesem Befund keine Bedentung zuzuschreiben, da ähnliche Bilder sich anch in dem linken Ganglion zeigten.

Die Gg. jugul. n. vagi normal.

Centralregion des Oculom otorius (Methylenblau, Weigert). Ich konnte nichts Abnormes finden. Eher möchte ich behaupten, dass das

Ganglion Habenulae beiderseits nicht ganz normal war. Ich fand nämlich viele Zellen mit wandständigem Kern, die Kerngrenze etwas verschwommen, einige Formen auffallend blass (keine deutliche Chromatolysis), andere sehr dunkel tingirt; da sich aber kein Unterschied zwischen rechts und links bemerken liess, und da man andererseits bei dem 11 Tage nach der Operation getödteten Thier nichts Abnormes feststellen konnte (Affe F, Versuch VIII), so kann ich diesem Befund keine besondere Wichtigkeit beilegen.

Centralregion des Abducens. Neben einigen, ziemlich normalen Zellen findet man rechts eine grosse Zahl theils Chromatolyse zeigender, theils geschrumpfter, missgebildeter Zellen, keine pyknomorphe Zellen; bei letzteren sind weder Kern noch Fortsätze zu sehen. Leider konnte ich nicht die ganze Serie verwerthen, da einige Schnitte durch verdorbene Toluidenblaulösung unbrauchbar waren; die Befunde beschränken sich auf die mit Methylenblan gefärbten Schnitte. Die Weigertsche Färbung zeigte normale intermedulläre Nervenfasern.

Die Centralregion des Trigeminus sowie das obere Cervicalmark (Methylenblau, We ig ert) waren normal.

Die Resultate dieses Experiments kann man folgendermaassen recapituliren: 24 Tage nach vorgenommener Neurectomia optiociliaris dextra mit Exstirpation des M. externus fand man Degeneration der rechten Ciliarnerven bis ins Ganglion ciliare, keine Degeneration weder in der Radix brevis noch im Ramus für den Obliquus inf., noch im Oculomotorius- 
Das Ne uron des Ganglion ciliare u. die Centra der Pupillenbewegungen. 395

stamm, wohl aber im rechten. N. abducens und rechten Opticus. Keine Degeneration der Fasern der VIII. Cervical-und I. u. II. Brustganglien, keine der ein- und austretenden Wurzeln und der betreffenden Rückenmarkssegmente. Degeneration einiger Zellengruppen des rechten G. Gasseri, keine Degeneration des rechten G. cerv. sup., noch der Centralregion des Oculomotorius, wohl aber Degeneration einer grossen Zahl vonZellen des rechten Abducenskerns. Die Ganglienzellen der Trigeminuskerne und des oberen Cervicalmarks sowie die Nervenfasern waren normal. Spärliche Zellen des linken G. ciliare zeigten eine partielle Chromatolyse; ob diese als ein accidenteller Befund oder in anderer Weise und wie zu deuten ist, bleibt eine offene Frage. ${ }^{1}$ )

\section{Resumé.}

Aus allen diesen Experimenten sieht man, dass die Befunde an Hunden und Affen sebr ähnlich sind.

Was das Ganglion ciliare an belangt, so kann man annehmen, dass nach Kauterisation der Cornea einige Zellen desselben mässig degeneriren; dasselbe findet man $n a c h$ einfacher Irideremie in einer grösseren Zahl von Elementen. Nach Irideremie mit Exstirpation einiger Ciliarfortsätze zeigt eine grössere Zahl von Ganglienzellen eine tiefere Degeneration, welche an Bedeutung und Extension zunimmt, wenn man den Bulbus entleert, und noch mehr, wenn man die Neurectomia ciliaris vornimmt.

Deutliche Degeneration der Ciliarnerven nehmen wir nach Eingriffen an den Ciliarprocessen und Ciliarnerven wahr. Nicht aber alle Fasern degeneriren und nicht alle in gleicher Weise; es scheint, dass einige widerstandsfähiger sind. Für die ziemlich normalen Fasern muss man annehmen, dass selbe vom Trauma nicht beschädigt worden sind, da ihr Gebiet sich ausserhalb des Experimentrayons befand. Man muss sich jedenfalls vor Augen halten, dass es sich um retrograde Degenerationen handelte. Diese Befunde stimmen im Grossen und Ganzen mit jenen Bernheimer's überein.

Wir haben ferner feststellen können, dass nach Eingriffen an der Cornea, an den Ciliarprocessen und-Nerven bei Hunden fast immer, bei Affen immer Degenerationen

1) Siehe Bemerkungen zu Affe E, Versuch VI. 
verschiedener Grade in verschiedenen Zellen und Zellengruppen des gleichseitigen Ganglion Gasseri vorkommen; dass sogar in einem Falle (Affe F, Versuch VIII) eine betimmte Zellengruppe diese Degenerationen zeigte. Somit gewinnen die Angaben jener Autoren, welche die Ciliares longi aus dem Ganglion Gasseri entspringen lassen, die experimentelle Stütze.

Höcht wahrscheinlich degeneriren bei Läsionen der Ciliarnerven auch einige Zellen des Ganglion cervicale sup; ich will das aber nur mit Vorbehalt angeben, weil bei Affe M(Versuch IX) eine deutliche Degeneration nicht vorhanden war (obwohl die Möglichkeit vorliegt, dass die stattgehabte Entartung nach 24 Tagen schon ausgeglichen war), hauptsächlich aber, weil wir noch sehr wenig über die Pathologie der sympathischen Zellen wissen und selbe eigenartige Charaktere besitzen ( $\mathrm{Nissl}\left({ }^{18}\right)$ ).

Man fand ferner, wie es vorauszusehen war, keine Degeneration der Zellen des Ganglion jugulare vagi, aber auch nicht der VIII. Cervical- und I. Brustganglien, sowie der betreffenden Rückenmarkssegmente.

Ich muss bemerken, dass mir die von Bernheimer angenommene Degeneration seiner Pupillencentra im Oculomotoriuskern zweifelhaft erscheint. Die Controlexperimente Bernheimer's und der anerkannte Ernst seiner wissenschaftlichen Arbeiten machten es mir zur Pflicht, mich sehr eingehend mit meinen Präparaten zu befassen. Leider konnte ich wegen Mangel an Material die Controlexperimente Bernheimer's nicht vornehmen, nahm jedoch 2 mal die experimentelle Verletzung des M. ext. vor und verfolgte deren Wirkung in der Centralregion. Der Unterschied war so auffällig, dass ich sagen konnte: die Oculomotoriuskerne sind normal, der Abducenskern ist krank.

Im Allgemeinen ist es schwer, mit Sicherheit Entartungen von Zellen nachzuweisen, wenn man keine identische Stelle vor Augen hat, und Bernheimer fand nach einseitiger Exenteratio bulbi beiderseitige Degeneration im grosszelligen Kern. Ich habe andererseits betont, wie verführerisch die Befunde ausfallen können; das wurde von verschiedenen Autoren hervorgehoben, und Nissl hat vor kurzer Zeit bemerkt, in welcher Weise sich die Verhältnisse durch Pykno-Apyknomorphie and Chromophilie compliciren. Endlich ist noch ein anderer Umstand zu berücksichtigen. Es wurde in dieser Arbeit zweimal gefunden, dass auch auf der nicht operirten Seite die Ganglienzellen in den verschiedensten Regionen nicht normal waren, und die Deutung dieser Ergebnisse stiess auf grosse Schwierigkeiten. Man kann nicht ohne Weiteres alle diese Befunde, auch wenn ihre Standorte mit 
Das Neuron des Ganglion ciliare u. die Centra der Pupillenbewegungen.

dem Experimente in einem wahrscheinlichen Zusammenhange stehen, ausschliesslich als durch das Experiment zu Grunde gegangene Zellen auffassen. Es giebt ja eine Menge anderer uns bekannter und unbekannter Ursachen, welche Alterationen der Nervenzellen bedingen können: so z. B. die allgemeine Reaction des Individuums, die Stärke des Traumas, welches auf das Centralnervensystem. weithin sich verbreiten kann, das Fieber, eine eventuelle Wundkrankheit u.s. w. Man muss auch die ungleiche Vulnerabilität der verschiedenen Zellen und Zelltheile berücksichtigen, und zwar äussert sich $\mathrm{Nis}$ i selbst vor Kurzem ${ }^{19}$ ) darüber folgendermaassen: „Die enorm leichte Zersetzbarkeit des färbbaren Bestandtheiles, namentlich aber das verschiedene Verhalten desselben in den einzelnen Zellen macht sich auch in der Technik in vielfach recht unangenehmer Weise geltend. Ueberlegt man, welch' minimale lebendige Kräfte nothwendig sind, um in unserem Gehirne die gewaltigsten Wirkungen hervorzubringen, so müssen wir nothwendig im Centralorgan Substanzen annehmen, deren Beschaffenheit es erlaubt, dass auf den geringsten Anstoss mächtige Stoffumsetzungen stattfinden".

Ich kann also nur meine negativen Befunde den positiven Bernheimer's für das cerebrale Centrum des Sphincter iridis entgegenstellen. Möglich, dass es sich um verschiedene Deutung des Beobachteten handle.

Negativ fielen auch meine Untersuchungen aus für die von anderen Autoren postulirten cerebralen Centra: so für die Umgebungen des III. Ventrikels, für das Ganglion habenulae (obwohl beim Affen M gerade dieses Ganglion beiderseits nicht ganz normal schien), so für das obere Cervicalmark, welches ich sowohl in Bezug auf Ganglienzellen als Nervenfasern normal gefunden habe, sowie für den Darkschewitsch'schen Kern.

Noch in einem anderen Punkt gehen die Befunde Bernheimer's und meine eignen auseinander. Bernheimer sagt, dass die motorische Wurzel des Oculomotorius nicht in das Ganglion ciliare aufgeht, sondern demselben nur anliegt; ich habe aber bei den Affen in allen untersuchten Ganglien gefunden, dass die motorische Wurzel in das Ganglion eingeht.

Als letzter Befund verdient hervorgehoben zu werden, dass die Degeneration der Ciliarnerven nicht durch das Ganglion ciliare sich fortpflanzt; in der That blieb die Radix brevis vollständig normal (Affe M, Versuch IX).

Es lag in meinem Arbeitsplan, ein weiteres Experiment auszuführen, und zwar wollte ich einen Oculomotorius an der Basis neurectomiren, um dann zu untersuchen, wie sich die intragangliären Nervenfasern 
und die Ciliares breves verhalten (A polant); das wäre gleichsam ein Gegenexperiment zu dem vorigen gewesen. Primararzt Dr. Es cher, Chirurg am Triester Civilspital, hatte die Gute, zweimal die Operation am Affencadaver vorzunehmen, wofür ich ihm herzlichst danke. Herr Dr. Es ch er führte die Operation so aus, als würde es sich um die Exstirpation des G. Gasseri nach Krause handeln, nur mit einigen Modificationen. Wir haben aber gesehen, dass, um zu dem fast an der Mittellinie der Basis laufenden Oculomotorius zu gelangen, das Gehirn sehr stark emporgehoben und deswegen der Knochen bis zur Sagittalfurche ausgemeisselt werden musste. Der Eingriff ist so bedeutend, dass nur ein sehr kräftiges Thier denselben zu überleben vermag. Leider konnte ich mir wegen der in Ostindien herrschenden Pest keinen Affen mehr verschaffen und musste deswegen das Experiment unterlassen.

Ich will hier endlich, um mit den Nebenfragen fertig zu werden, hervorheben, dass meine Befunde an Affen eine Bestätigung dafür sind, dass ein Theil der Ciliarfasern (longi?) mit dem Ganglion Gasseri im Zusammenhang steht, ja, dass dieselben aus diesem Ganglion entspringen. Nicht mit der gleichen Gewissheit darf man annehmen, dass die sympathischen Fasern aus dem Ganglion cervic. sup. abstammen, da man aber in fast allen Fällen etwas Pathologisches mit Sicherheit an den Zellen des G. cerv. sup. auf der operirten Seite gefunden hat, und da, wie wir gleich sehen werden, ein sehr enger Connex zwischen erweiternden Pupillenfasern und jenem Ganglion von Langley gefunden worden ist, so muss man doch als höchst wahrscheinlich annehmen, dass meine Befunde in dieser Weise zu deuten sind.

Und nun noch eine Reihe von Versuchen, welche für die mich am meisten interessirende Frage von hoher Wichtigkeit sind:

\section{Nicotinversuche.1)}

Bevor ich über eigene Experimente weiter berichte, muss ich die Arbeiten von Langley nach der ausgezeichneten Zusammenstellung, die Bottazzi( $\left.{ }^{20}\right)$ vor Kurzem publicirte, besprechen.

Langley und Dickinson, von einer Beobachtung Hirschmann's (1863)ausgehend, welcher keine Pupillenerweiterung bei Reizung des Halssympathicus nach Nicotineinspritzung nachweisen konnte, verfolgten

1) Ich spreche Herrn Dr. Vierthaler, Prof. der Chemie in der hiesigen Handelsacademie, welcher so freundlich war, mir die Substanz bereitwillig zur Verfügung zu stellen, meinen besten Dank aus. 
Das Neuron des Ganglion ciliare u. die Centra der Pupillenbewegungen. 399

diese Versuche mit grosser Sorgfalt und konnten die Angaben Hirschmann's vollkommen bestätigen und die Studien erweitern. Nach Nicotineinspritzungen oder-Betupfungen war bei Reizung des Sympathicus unter dem Ganglion keine Reaction der Pupille und keine Contraction der Ohrgefässe zu beobachten, wenn jedoch die Reizung oberhalb des Ganglions stattfand, traten dieselben ein. Sie kamen zu dem Schlusse, dass Nicotin wohl die Ganglienzellen des Sympathicus, nicht aber die Fasern und die Nervenendigungen paralysirt. Das Gleiche gilt für das Ganglion solare und für die Splanchnici.

Die Fasern des III. Pares, welche zur Iris und zum Ciliarmuskel ziehen, stehen mit Zellen des Ciliarganglions in Beziehung. Eine kleine Nicotindosis (6 Milligramm) lähmt auf einige Zeit die Nervenzellen des Ciliarganglions, so dass die Impulse, welche durch diese Zellen längs der Oculomotoriusfasern durchziehen, ausgeschlossen werden. Eine grössere Nicotindosis (100 Milligramm) vermag die Nervenendigungen der Ciliares breves in der Iris und im Ciliarmuskel nicht zu paralysiren.

Bei der Erweiterung der Pupille sind die I., II. und III. Brustnerven immer thätig.

Interessant sind auch folgende Beobachtungen(21). Eine frühere Untersuchung hatte gezeigt, dass bei Katzen der I.-VII. Brustnerv Verbindungsfäden zum Grenzstrang des Sympathicus senden, deren jeder einer ganz bestimmten Function vorsteht. Der I. Brustnerv z. B. giebt die Fasern für die Pupille, der II. für die Ohrgefässe u. s. w. Langley hat die Durchschneidung des Sympathicus unterhalb des Ganglion cervicale sup. an einem Kätzchen vorgenommen und das Thier ein Jahr nach der Operation einer Untersuchung unterzogen, indem er jeden einzelnen Brustnerv elektrisch reizte. Es zeigte sich, dass alle Nerven nur die ihnen der Regel nach zukommenden Functionen besassen: so z. B. der I. Brustnerv nur die Pupillenfasern, der II. die Ohrgefässe u. s. w. Man muss sich also vorstellen, dass die neugebildeten Fasern gerade die entsprechenden Ganglienzellen im Ganglion cervic. sup. aufgesucht hatten und mit ihnen in Verbindung getreten waren. Dass die Fasern etwa das Ganglion einfach durchsetzt hätten, ohne in Verbindung mit dessen Zellen zu treten, wird dadurch widerlegt, dass durch Betupfen des Ganglions mit Nicotinlösung die Wirkung des peripherischen elektrischen Reizes so gut wie ganz vernichtet ward e.

Langley hat weiter ein neues Experiment ausgeführt: Der centrale Stumpf des Vagus wurde knapp unter dem Larynx durchgeschnitten und mit dem peripheren Stumpf des Halssympathicus 
verbunden. Nach 73-123 Tagen hatte die Reizung des Sympathicus in der unteren Halsregion (centraler Stumpf) keinen Effect; dieser Stumpf hatte also keine functionelle Verbindung mit dem peripheren Stumpf. Die Reizung des Sympathicus knapp unter dem Ganglion cerv. sup. löste ähnliche Reflexe aus, wie bei Reizung des Vagus; diese Wirkung verschwand sofort, wenn man den Vagus in der Nähe des G. thorac. durchschnitten hatte. Es folgt daraus, dass Fibrae afferentes vagi peripherisch regenerirt und mit dem peripheren Stumpf des Sympathicus verbunden waren; die Vagusreizung etwas unter dem eigenen Ganglion (der Nerv war centralwärts von dieser Stelle durchschnitten). bewirkte Pupillendilatation und andere Symptome der Sympathicusreizung.

Langley nimmt an, dass die Fibrae efferentes vagi längs dem peripheren Stumpf des Sympathicus regenerirt waren und sich neue Endigungen zwischen den Zellen des G. symp. sup. gebildet hatten. Langley glaubt deswegen, dass kein Unterschied unter den Fibrae efferentes bestehe, welche durch den Kopf- oder Spinalnerven zum Sympathicus ziehen. Langley nimmt schliesslich an, dass jedes Ganglicii ues Synpathicussystems als ein Hauptcentrum, unabhängig von jeder Verbindung mit dem Rückenmark, betrachtet werden müsse.

Die Fasern ziehen hauptsächlich gegen den entsprechenden Spinalnerv und folgen demselben, sie sind mit allen jenen peripheren Gebilden verbunden, mit welchen die symp. Fasern in Beziehung treten können, so zwar, dass die Function derselben nicht nach der Natur der Nervenfasern, sondern nach den Organen, wo sie enden, bestimmt wird.

Nach Besprechung dieser neuen, bahnbrechenden Studien und Schlussfolgerungen Langley's werde ich über meine Experimente mit Nicotin berichten.

Es wurde von Dr. Cofler und mir folgendermaassen experimentirt:

Exper. I. Nachdem bei Affe L (Vers. V) der Zustand der Pupille, die Corneaempfindlichkeit, die Weite der Gefässe der Conjunctiva, der Retina und der Papilla, die Spannung des Bulbus am linken Auge (das rechte war operirt) bestimmt waren (normal), injicirte Herr Dr. Cofler mit einer Pravaz zwischen Bulbus und äusserer Orbitalwand, tief nach unten eindringend, $6 \mathrm{mg}$. Nicotin (eine halbe Pravaz'sche Spritze einer 1,20:100,0 Nicotinlösung).

Es entstand sofort Oedema palp. und Exophthalmus, nach einer Minute Mydriasis, die Pupille war aber nach 2 Minuten wieder normal.

Nach 5 Minuten Mydriasis nicht maximalen Grades, die Reaction existirt, sie ist aber träge und danert sehr kurz. 
Das Neuron des Ganglion ciliare u. die Centra der Pupillenbewegungen. 401

Nach 7 Minuten ist die Pupillenreaction noch immer mangelhaft, die Sensibilität der Cornea normal.

Nach 20 Minuten Anästhesie der Cornea; Pupille reagirt sehr träge, kaum sichtbar. Ophthalmoskopisch keine Veränderung der Gefässe, die Spannung war die gleiche. Starke Benommenheit des Thieres.

Nach 30 Min. war alles zur Norm zurückgekehrt.

Exper. II. An demselben Affen wurde Tags darauf eine doppeltgrosse .Dosis Nicotin (1 volle Pravaz'sche Spritze) in derselben Weise eingespritzt. Starkes Oedema palp. and Exophthalmus. Gleich Mydriasis und Unbeweglickeit der Lider.

Nach 1 Minute: Die Mydriasis wird weniger intensiv, die Pupillenreaction existirt, aber unvollständig, träge und ist von kurzer Dauer. Scheinbare Anästhesie der Cornea.

Nach 6 Minuten ist die Pupille ad maximum dilatirt und unbeweglich bei Lichteinfall und Convergenz; scheinbare Anästhesie der Cornea. Ophthalmoskopischer Befund, Spannung des Bulbus normal.

Nach 10 Minuten: Pupille wie zuvor. Jetzt bemerkt man, dass, obwohl bei Reizung der Cornea die Lider derselben Seite unbeweglich bleiben, die Lider der anderen (rechten) Seite sich aber reflectorisch bei jeder Berührung der linken Cornea schliessen.

Nach 25 Minuten ist die Mydriasis vielleicht etwas weniger ausgesprochen, die Pupillarreaction immer Null. Bei Reizung der Cornea dieselben Erscheinungen.

Nach 40 Minuten ist die Pupillarreaction kaum bemerkbar, Mydriasis; bei Reizung der Cornea träger Lidschluss auf dem injicirten Auge, das Oedem ist fast verschwunden.

Nach 50 Min. ist die Pupillarreaction ganz deutlich, obwohl noch unvollständig und flüchtig, fast gar keine Mydriasis, Cornealreflex fast normal.

Das Thier wird in seinen Käfig gebracht, zeigt allgemeines Zittern, Unbeholfenheit, ja Ataxie bei Bewegungen. Tags daranf war der Affe vollkommen normal.

Exper. IIT. Zur Controle injicirt Dr. Cofler nach 24 Stunden demselben Thier nach der angegebenen Methode $10 \mathrm{ccm}$ destillirtes Wasser: Oedem und Protrusion des Bulbus wie bei dem Exper. II. Keine Veränderung der Pupille, die Lider des injicirten Auges schliessen sich trotz des Oedems jedesmal, wenn man die Cornea reizt.

Obwohl die Ergebnisse klar und unzweideutig, was die Lähmung des Sphincter. anbelangt, waren, so schienen mir einige Punkte noch dunkel, nämlich die Frage der eventuellen Parese des Orbicularis und der Sensibilität der Cornea. Ich wollte ferner das Verhalten des zweiten Auges stu. diren, was bei jenem Thier wegen der schon ausgeführten Operation am rechten Ange nicht möglich war. So entschloss ich mich, an einem anderen Affen das Experiment zu wiederholen.

Exper. IV. Am 6. Juni injicirte Herr Dr. Cofler in der angegebenen Weise $6 \mathrm{mg}(1 / 2$ Pravaz) Nicotin am linken Auge eines mittelgrossen 
Thiers. Es traten keine localen Symptome, dafïr aber schwere allgemeine Erscheinungen auf, so zwar, dass wir der Meinung waren, das Thier bleibe nicht am Leben. Cyanose, Kälte der Nase und der Extremitäten, Erbrechen, Dyspnoe, Sopor, Ptosis links (Oedem der Lider?). In den Käfig gebracht, bleibt das Thier ganz zusammengeballt und scheint nicht ganz bei sich zu sein. Am anderen Tag war es ganz munter.

Exper. V. Am 12. Juni wurde an einem anderen nicht operirten Affen (Affe M, Vers. IX) experimentirt und zwar mit sehr interessanten Ergebnissen.

An dem kleinen Thier wurden nach der üblichen Methode $6 \mathrm{mg}$ Nicotin links injicirt. Sofort Oedem beider Lider, stärker am oberen.

Nach einer Minute trat Erweiterung der linken Pupille und träge Reaction ein, während die rechte von ganz normaler Weite blieb und gut reagirte.

Nach 5 Minuten nur links fast maximale Mydriasis und Unbeweglichkeit bei Lichteinfall und Convergenz. Cyanose, Benommenheit, Cornealreflex in gleicher Weise sowohl rechts als links vermindert. Verengerung der Lidspalte links (Oedem), keine Ptosis. Keine Parese des Orbicularis. Erbrechen, starke Benommenheit, das Thier b leibt ruhig und reagirt gar nicht bei den verschiedenen Untersuchungen. Ophthalmoskopisch normale Verhältnisse sowohl rechts als links. Spannung des Bulbus normal, beiderseits gleich.

Die Mydriasis mit Pupillenstarre danerte fast eine ganze Stunde. Wiederholte Untersuchungen der Cornealempfindung ergaben immer denselben angegebenen Befund; sei es, dass man rechts oder links reizte, es war kein Unterschied in dem Reflex zwischen rechts and links zu bemerken.

Nach anderthalb Stunden war die Reaction der linken Pupille normal, der Cornealreflex noch nicht ganz prompt weder rechts noch links; Oedem vermindert, aber noch deutlich.

Das Thier wurde in seinen Käfig gebracht. Keine Ataxie, leichter Sopor, auffallende Ruhe, Nahrungsverweigerung; wenn man es reizt, Abwehrbewegungen mit dem Kopf.

Da dieses Experiment so vollständig gelungen war und das Thier die kleine Dosis im Gegensatz zum ersten nicht gut vertragen hatte, habe ich von einer zweiten Injection mit einer stärkeren Dosis Abstand genommen.

Das IV. Experiment hat für uns einen geringen Werth, weil das Nicotin nur allgemeine Symptome hervorrief, leider wurde dabei auf die Sensibilität der Cornea nicht geachtet.

Bei dem ersten Versuch glaubten wir eine Anästhesie der Cornea annehmen zu dürfen, wir hatten aber wahrscheinlich mit einer Parese des Orbicularis oder mit einer Reflexhemmung zu thun. In der That konnte man bei dem zweiten Versuch von einer Anästhesie der Cornea nicht sprechen, da die Lider des anderen Auges ziemlich prompt und jedesmal bei Berührung der linken Cornea zuckten.

Das fünfte Experiment bestätigte unwiderleglich, dass die Sensibilität der Cornea der operirten Seite keinen Unterschied im Vergleich zu der der anderen Seite darbot. Die beiderseitige verminderte, 
Das Neuron des Ganglion ciliare u. die Centra der Pupillenbewegungen.

träge Reaction der Lider bei Reizung einer Cornea wäre somit als der Ausdruck geschwächter Reflexe, als ein Theil der allgemeinen Erscheinungen aufzufassen. Es ist also anzunehmen, dass durch das Gift, bei intacter Leitung, eine Hemmung dort eintrat, wo die centripetalen in centrifugale Reize umgewandelt werden.

Dieselbe Bedeutung konnte auch die Parese des Orbicularis bei dem ersten Affen haben, nur war hier das Phänomen einseitig.

Ausser jedem $\mathrm{Z}_{\text {weifel }}$ ist die eingetretene Lähmung des Sphincter iridis; sie war constant und lange Zeit anhaltend. Von Bedeutung ist auch, dass nur der Sphincter gelähmt war, in der That bot die Pupille eine Weite dar, wie sie nur bei activer Action des Dilatators möglich ist. Damit ist wieder der Beweis gegeben, dass die Ciliarfasern nicht afficirt waren, sonst hätten auch die Dilatatoren gelähmt sein müssen.

Diesem Experimente nach hat das Ganglion ciliare nur eine Function; die Innervation des Sphincter iridis, denn sowohl eine Anästhesie der Cornea, wie man im Anfang annahm, als eine Wirkung des Ganglion ciliare auf die Gefässe der Papilla und der Retina oder auf die Spannung des Bulbus sind diesen Versuchen nach, auszuschliessen.

Als letztes Ergebniss fanden wir mit Langley, dass das Ganglion eiliare auch bei Affen sich zum Nicotin wie ein sympathisches Ganglion, wenigstens was die Pupillenverengerung anbelangt, verhält.

Wie sind aber die verschiedenen Resultate des IV. Versuchs (beim zweiten Affen) zu deuten, bei welchem keine localen Symptome und nur schwere Allgemeinerscheinungen zu beobachten waren? Es giebt zwei Möglichkeiten: entweder war das G. ciliare bei diesem Affen mit wenigstens vorwiegend spinalen Elementen versehen (das Thier wurde nicht getödtet), oder, was viel wahrscheinlicher ist, das Gift drang augenblicklich in den Blutstrom ein und konnte somit nur schwere allgemeine Intoxicationserscheinungen und keine localen Symptome hervorrufen.

Auffallend ist die Wirkung auf die Pupille bei der in der angegebenen Weise ausgeftuhrten acuten den chronischen Vergiftungen von Pándi( $\left.{ }^{22}\right)$ gegenüber. Ich fand immer Mydriasis, Pándi immer Myosis.

Dies sind meine auf die Sätze Langley's sich stützenden Nicotinversuche, deren Verlauf und Deutung durch Herrn Dr. Cofler mit gewohnter Liebenswürdigkeit controlirt wurde. 
Die Bedentung des Ganglion ciliare für die Verengerung der Pupille.

Wenn die angewendeten Methoden verlässlich sind, so sind die logischen Schlussfolgerungen meiner Experimente, was das Ganglion ciliare anbelangt, nicht schwer zu ziehen.

I. Da bei den Affen, sagen wir nach Bernheimer ein fünfsechstel Theil der Zellen des Ciliarganglions nach Kauterisation der Cornea degenerirt sind, so ist der fünf-sechstel Theil der Zellen sensorischer Natur und bei der Sensibilität der Cornea thätig.

Um den mit dieser. Annahme widersprechenden Nicotinversuch, nach welchem man eine sensible Function des Ciliarganglions für die Cornea vermisste, in Einklang zu bringen, giebt es nur zwei Hypothesen: entweder waren die gefundenen Alterationen der Ganglienzellen nach Kauterisation der Cornea mit dem Experiment in keinem causalen Nexus - was nach den übereinstimmenden Befunden von Bernheimer bei den Affen, von mir bei Affen und Hunden unwahrscheinlich ist - ; oder es lähmt das Nicotin die sensorischen Zellen des Ciliarganglions nicht, weil diese nicht sympathische, sondern spinale Zellen sind.

II. Da in Folge der Exenteratio bulbi und der Neurectomia optico-ciliaris, also nach Verletzung der Nerven, welche a ach die Binnenmuskeln der Augen innerviren, alle Zellen des Ganglions mehr oder weniger degeneriren, so folgt daraus, dass die grösste Mehrzahl der Ganglienzellen eine motorische Function besitzt, eine Function, welche durch das physiologische Experiment (Nicotin) deutlicher hervortrat, nämlich die Innervation des Sphincter iridis.

Aus diesen Schlüssen folgt, dass das Ganglion ciliare bei Affen böchstwahrscheinlich wenig spinale, aber viel sympathische Zellen besitzt, ferner dass das G. ciliare bei Affen wirklich ein Centrum der Pupillenbewegungen, ja nach meinen Experimenten sogar das einzige, wirklich nachgewiesene Centrum für die Pupillenverengerung ist.

Und nun zu den Einwänden, welche ausschljesslich von Bernheimer vorgebracht wurden, weil er eben der Einzige ist, welcher meine Hypothese über die Bedeutung des $G$. ciliare für die Pupillenbewegungen eingehend erörtert hat!

Bernheimer äussert sich nicht mit Sicherheit über die Natur des 
Das Neuron des Ganglion ciliare u. die Centra der Pupillenbewegungen. 405

G. ciliare, er sagt ${ }^{1}$ ): „Am besten ist unser Experiment in Einklang zu bringen mit der Annahme Jener, welche das G. ciliare für ein sensorisches (His u. A.) oder für ein gemischtes (Krause) halten".

Mir dünkt es aber, dass Bernheimer sich mehr für die sensorische Natur ausspricht, denn in dem Sitzungsprotokoll der Wien. Gesellsch. der Aerzte ist Folgendes zu lesen:

„Es schien mir von vornherein unwahrscheinlich, dass das G. ciliare als eine Art peripheres Centrum der Irismuskeln aufgefasst werden konnte, da wir der Annahme huldigen, dass dies Ganglion wie alle peripheren Ganglien ein sensorisches sei."

Dem gegenüber will ich nur erinnern, dass Coutarde und Guyon $\left({ }^{23}\right)$ durch Experimente über die reflectorische Function des Ganglion mesentericum zu dem Schlusse gelangten, dass der Reflex im Ganglion selbst sich abspielt.

Weiter sagt Bernheimer: „Hiermit ist der Beweis geliefert, dass das Ganglion ciliare thatsächlich ein sensorisches Ganglion ist, und dass die von ihm abgehenden Ciliarnerven sensorische Nerven sind, welche die Hornhaut, die Binnenmuskeln und die Augenhäute überhaupt versorgen."

Ich denke, man kann nicht so leicht mit Bernheimer einverstanden sein, wenn er von sensorischen Nerven für die Binnenmuskeln spricht. ${ }^{2}$ ) Würde es sich um willkürliche Muskeln handeln, deren Contraction mit dem Bewusstsein und dem Willen in einem engen Connex stehen, so wäre es annehmbar; es wäre eine Vermittlung des sogenannten Muskelsinns. Aber es giebt fürwahr keine Muskeln, deren Contraction weniger zum Bewusstsein gelangt, als die der Binnenmuskeln des Auges, und das Organ wäre kaum das geeignete.

Ein Organ wie das G. ciliare, welches bei allen Vertebraten sich findet, von den kleinen Zellenlagen anfangend, immer mehr wachsend und sich differenzirend, um bei den höheren Wirbelthieren, beim Affen und Menschen zur stattlichen Grösse eines Ganglion zu gelangen, muss, wie Antonelli ganz richtig betont, und wie es selbstverständlich ist, eine hohe Bedeutung haben. Die motorische Innervation des Sphincters und wahrscheinlich auch des Brücke'schen Muskels, vielleicht eine coordinatorische Action zwischen erweiternden, verengernden und auch sensiblen, aus dem Trigeminus stammenden Fasern sind eben Functionen, die einen hohen biologischen Werth besitzen.

In der That sagt Schwalbe, dass die Faserzahl der austretenden Ciliarnerven eine bedeutend grössere ist, als die der eintretenden drei

1) 1. c. $\$$. 536 .

2) Die dicke Schrift wurde von mir angewendet. 
Wurzeln, so dass demnach im Innern des Ganglion eine bedeutende Faservermehrung in Verbindung mit dem Auftreten von Ganglienzellen statuirt werden muss.

Ein nur die Empfindlichkeit eines glatten Muskels vermittelndes Organ, für welche Function schon die mächtigen Neurone des Trigeminus da sind, hätte wahrscheinlich keine solche Ausbildung und Differenzirung erreicht.

Die grosse Bedeutung des G. ciliare für die Irisbewegung hat Jendrássik $\left({ }^{24}\right)$ in einer tiefgedachten Arbeit geahnt. Es ist mir leider nicht möglich, auf diese wichtige Arbeit näher einzugehen, einen Punkt muss ich aber hervorheben. Obwohl es scheint, dass er das G. ciliare nicht als Centrum der Pupillenverengerung annimmt, sagt er S. 456: „Diese Verhältnisse sind ähnlich dem Verhalten der Pupille, wo die Verbindung des G. ciliare mit der Iris selbst bei Oculomotoriuslähmung gewöhnlich intact bleibt, was man bisher vernachlässigt bat, und doch können wir in dieser Einrichtung die Erklärung für manche bekannte und bisher nicht richtig erkannte Erscheinungen finden."

Bernheimer sagt ferner (S. 536): „Dass es sich (bei isolirter Pupillenstarre) um eine elective primäre Erkrankung jener Ganglienzellen handle, welche Nervenfasern zur Iris und zum Ciliarkörper senden, ist wohl von vornherein ausgeschlossen, um so mehr, da in den einzelnen Schnitten vielfach degenerirte und normale Zellen miteinander vermischt waren."

Es scheint mir, dass eine elective Erkrankung wohl möglich sei, nnd eben weil bei den Experimenten in den Schnitten degenerirte und normale Zellen vermischt waren, je nachdem die Cornea oder die Ciliarnerven verletzt wurden, ist es wohl denkbar, dass die degenerirten Elemente mit dem zerstörten Organ im Zusammenhang waren, die anderen nicht. Der Nicotinversuch sagt uns, dass es wahrscheinlich spinale Zellen sind, welche die Sensibilität der Cornea besorgen; es ist wohl möglich, dass diese, der Krankheit gegenüber, einen grösseren Widerstand leisten als die anderen.

In der Nervenpathologie ist etwas Aehnliches zu beobachten. Bei der Bulbärparalyse z. B. kann die ganze Kette der motorischen Bulbärgruppe erkranken und die sensiblen Nerven können frei bleiben, ja wir beobachten Lähmung der Masseteren bei intacter Sensibilität des Gesichtes, also ein verschiedenes Verhalten von Territorien, welche von demselben Nervenstamm (Trigeminus) innervirt werden.

Das Nicotinexperiment zeigt uns nach Langley, dass sympathische Elemente im G. ciliare in sehr grosser Zahl vorhanden sein müssen. In diesem Falle kann aber die Function derselben nach Kölliker und Jend rássik nur motorisch sein, und in derThat ist die alleinige 
Wirkung des Nicotins eine Lähmung des Sphincter iridis." Andererseits haben wir gesehen, dass sich im G. ciliare Zellen finden, welche mit der Cornea in functioneller Beziehung stehen, die nämlich eine centripetale Function besitzen; es ist also natürlich, dass elective Wirkungen vorhanden seien und dass die Zellen electiv erkranken können.

Ich habe ferner in der lehrreichen Arbeit Ant on elli's einige Experimente ron Jegorow (25) kennen gelernt, welche meine Experimente mit Nicotin glänzend ergänzen; ich habe nach Langley das G. ciliare durch dieses Mittel, Jegorow hat es mit dem Messer ausgeschaltet; wenn aber J. auch die Rad. brevis dadurch getrennt hat, so ist mein Experiment einwandsfreier. Ich konnte leider das Original nicht bekommen, deswegen übersetze ich aus dem Antonelli'schen Referat:

Jegorow, den Experimenten Birhard's folgend, hat sehr eingehende Untersuchungen gemacht, um die Function des G. ciliare zu bestimmen. Die Reizung dieses Organs war in ihrer miotischen Wirkung viel wirksamer, als die Reizung des peripheren Oculomotoriusstumpfes ${ }^{1}$ ), wie andererseits die Mydriasis deutlicher auftrat nach der Durchschneidung der Ciliares breves, als nach der des Oculomotorius. Auf das Caliber der Endoculargefässe hatte die Reizung sowohl des Ganglions als des Oculomotorius keinen Effect. Auf die vollständige bei neun Thieren ausgeführte Excision des Ganglions folgte, von einer Läsion der Cornea sehr zweifelhafter Natur und Bedeutung abgesehen, hochgradige Mydriasis mit Pupillenstarre, keine circulatorische Veränderung im Auge (höchstens eine flüchtige Erweiterung der Retinalgefässe), keine Veränderung der endocularen Tension. Kurze Zeit nach der Operation fand man Atrophie und Degeneration der Nn. ciliares breves. Aus diesen experimentellen Ergebnissen deducirt man, dass die physiologische Dignität des Ganglion ciliare durch einen trophischen Einfluss sich kundgiebt, welchen die Ganglienzellen auf die durchziehenden Nervenfasern ausüben.

Die Experimente sind gewiss geistreich, wie man aber in dieser Schlussfolgerung die Wirkung der für Gesetze gehaltenen Theorien fühlt! In der That, wird durch ein Experiment oder durch eine Krankheit eine bestimmte Zellengruppe im Pons ausgeschaltet oder zerstört und resultirt daraus eine Lähmung eines Facialis mit Fntartung des betreffenden Nerven, so sagen wir nicht nur, dass diese Zellengruppe eine trophische Wirkung auf jene Nervenfasern ausübt, welche von dem corticalen Facialiscentrum hinziehen, sondern dass diese Zellen das motorische Centrum des Facialis sind. Warum soll man für das Ganglion ciliare einen anderen Gedankengang gebrauchen?

1) Langendorff fand bei Reizung des Oculomotoriusstammes keine Wirkung, Schultz Verengerung. 
van Gehuchten $\left.{ }^{26}\right)$ lässt sich von Theorien in seinen Schlussfolgerungen nicht abschrecken, er geht mit consequenter Logik zum Schlusse, und, obwohl ihm meine vor drei Jahren erschienene Arbeit entgangen ist, schreibt er: „D’après des recherches éxperimentales récentes, les fibres du nerf oculomoteur commun, sectionnées au sortir da mésencephale, ne dégénèrent que jusque dans le ganglion ciliare. $\mathrm{Si}$ ce fait se confirme, on devrait en tirer la conclusion que les fibres motrices, amenées au ganglion ciliare par la branche afférente emanée du nerf oculomoteur commune, se terminent dans ce ganglion par des ramifications libres et que, par conséquent, les cellules d'origine des fibres qui innervent les muscles intrinséques du globe oculaire se trouvent dans le ganglion ciliaire lui même. Ce fait aurait une importance considerable au point de vue physiologique, parce qu'il tendrait à prouver que le centre du réflexe pupillaire se trouve, non pas dans le noyau d'origine du nerf de. la troisième paire comme on le croit generalement, mais bien dans le ganglion ophthalmique".

van Gehuchten denkt an die Ergebnisse der Apolant'schen Versuche, welche ich schon wiedergegeben habe, und die von mir durch Versuche in umgekehrter Richtung bestätigt worden sind, denn ich habe ja gefunden, dass nach Neurectomia optico-ciliaris die Ciliarnerven nur bis zum Ganglion degeneriren und die Degeneration nicht auf die Radix brevis übergeht.

Dieser Befund ist ferner in Einklang zu bringen anch mit dem Schema Schultz's ( $\left.{ }^{27}\right)$, in welchem er die Oculomotoriusfasern im Ganglion ciliare frei enden lässt. Dieser Autor äussert sich ohne Reserve in folgender Weise (S. 49): „Das Ganglion ciliare ist ein sympathisches Ganglion, es gehört zum N. oculomotorius und zu keinem anderen Nerven. Es endigen sämmtliche in das Ganglion eintretende Fasern des Oculomotorius hier mit freien Endbäumchen, und an diese schliessen sich die sympathischen Endneurone an, die also, ohne dass sich noch einmal Zellen zwischenschieben, direct zum Ciliarmuskel und zum Sphincter ziehen."

Die Bedeutung also des G. ciliare für die Verengerung der Pupille ist nach alledem einleuchtend; wie steht es aber mit dem cerebralen Centrum der Pupillenbewegungen?

Ich habe, wie gesagt, mit Bach eine Degeneration der Bernheimer'schen Kerne nicht finden können, damit ist aber nicht gesagt, dass nicht ein Centrum existire, und vielleicht auch, dass gerade jene Kerne das Centrum seien. Ich habe keine Degeneration, weder in Zellen noch in den Strängen noch in den Wurzeln des VIII. Cervicalund I. and II. Brustsegments gefunden, und die physiologischen Experi- 
Das Neuron des Ganglion ciliare u. die Centra der Pupillenbewegungen. 409

mente schreiben doch dieser Region eine grosse Bedeutung für die erweiternden Pupillenfasern zu. Also das „Nichtfinden“ hat kein „Nichtsein" zur Folge. Es ist möglich, dass die Degeneration nach Eingriffen auf die peripheren pupillenerweiternden und -verengernden Apparate das erste periphere Neuron nicht überschreitet.

Ich will also für einen Augenblick zugeben, dass Bernheimer Recht hat, und dass seine Kerne wirklich Pupillencentra sind, warum soll aber das Experiment zweideutig interpretirt werden? Wenn nach der Exenteratio bulbi das Ganglion ciliare und die Bernheimer'schen Kerne degeneriren, so folgt daraus, dass entweder beide oder keines als Centrum der Pupillenbewegungen angesehen werden darf. Obersteiner äusserte sich ja in der Discussion über den Bernheimer'schen Vortrag folgendermaassen: „Es darf ja angenommen werden, dass bei diesen Vorgängen eine ganze Anzahl von Neuronen in Action trete, so dass ein eigentliches Reflexcentrum nicht abgrenzbar erscheint."

Ich hoffe nach dieser Erörterung die Sache so weit gebracht zu haben, dass man annehmen wird, das Ganglion ciliare sei ein Centrum für die pupillenverengernden Fasern. Wenn es sich so verhält, so ergiebt sich für die Physiologie des Nervensystems eine wichtige Folgerung.

Da bei fast allen Vertebraten der Pupillenreflex existirt, sei es bei Vögeln, bei welchen nach Holtzmann die Ciliarganglienzellen spinaler Natur sind, sei es bei Katzen, bei welchen die Zellen sympathischer, sei es bei Hunden, bei welchen sie gemischter Natur sind, so folgt in logischer Weise, dass der sympathische oder spinale Charakter der Zellen für die Function derselben gleichgültig ist, und dass die Function der Zellen nicht von dem Charakter derselben, sondern von ihrem peripheren Endorgan bestimmt wird. Ja, es ist vielleicht das Endorgan, wo der Nervenfortsatz sich ausbreitet, es sind die specifischen Reize diejenigen, welche den Abkömmlingen der Intervertebralganglien den Typus einprägen, nicht umgekehrt. Benda (28) sagte vor Kurzem: „Diese (Herznerven) entstammen zwar den Spinalganglien, die schliesslich nur sensible Zellen enthalten, die Spinalganglien selbst gehen aber aus der gemeinsamen Anlage des Medullarrohrs hervor, das motorische und sensible Elemente enthält. Der Charakter der Ganglienzellen wird durch die Richtung und Verbindung der Zellenausläufer bestimmt."

Ich will hier nicht die von mir gegebene und von Bernheimer als ,bedenklich" bezeichnete Hypothese über die reflectorische Pupillenstarre discutiren; es ist noch verfrtiht sich in eine solche Frage zu vertiefen, da die Physiologie des Neurons des Ganglion ciliare, ein für die Pupillenbewegungen so wichtiges Organ, nur die ersten Schritte 
gemacht hat ${ }^{1}$ ) und die Pathologie desselben von Grund aus zu schaffen ist; ich musste in meinem Buch auf dieses Phänomen eingehen, weil das Studium rein klinisch war. Hier liegt die Sache anders; ich habe getrachtet mich streng an meine Experimente zu halten, die Ergebnisse derselben objectiv zu beurtheilen und nur die naturliche, logische Folge zu ziehen; ich will in keine weiteren Hypothesen eingehen.

Fürwahr ist eine Beurtheilung der Action des G. ciliare noch unmöglich, denn man weiss zu wenig über die Function der Ganglien überhaupt, und dann denke man nur, wie viele in Thätigkeit versetzte Nervenstationen nothwendig sind, damit die Lichtreizung und Convergenz eine Verengerung der Pupille verursachen, wie zertbeilt in jeder Station die Umwandlung der Spaunkraft in lebendige Kräfte sein muss und wie schwer man bestimmen kann, welche Station die wichtigste ist!

Ich kann aber nicht unterlassen zu bemerken, dass die logischen, sich auf das klinische Studium der 250 Fälle von Augenmuskellähmungen sich stützenden Folgerungen - wie selbe im Capitel über die Pupillenreactionen am Schlusse meiner citirten Arbeit niedergeschrieben sind - durch diese Experimente eine erhebliche Stütze erfahren; auch das Experiment sagt uns, dass das G. ciliare ein Centrum - und was für eines! - der Pupillenbewegungen sein muss; nun wird die menschliche Pathologie an die Reihe kommen, denn das Experiment kann nur als Leitfaden dienen. Ich hoffe in einer künftigen Publication über jene Ergebuisse berichten zu können.

Ich erfülle hiermit eine freudige Pflicht, wenn ich meinem geschätzten Freunde, dem Herrn Prosector des hiesigen Civilspitals, Dr. Pertot, welcher mir bereitwilligst das städtische Laboratorium zur Verfügung stellte, meinen verbindlichsten Dank ausspreche.

Am Schlusse dieser Studie kann ich ferner nicht umhin, noch einmal meinem ausgezeichneten Mitarbeiter, Herrn Dr. Cofler, sowie meinem guten Freund, dem vorzüglichen Zeichner Herrn Prof. Cortivo, meine tiefe Dankbarkeit auszusprechen.

1) Für die Physiologie des G. ciliare und der symp. Ganglien im Allgemeinen verweise ich auf die citirte Arbeit Jendrássik's und auf die neue wichtige experimentelle Studie von Schultz (29). Leider kann ich dieselben weder referiren noch discutiren; es wäre daraus ersichtlich, wie wenig man weiss und mit welcher Mühe man nach Licht strebt.

Trest, November 1898. 


\section{Literaturverzeichniss.}

1. A. Marina, Ueber multiple Augenmuskellähmungen und ihre Beziehungen zu den sie bedingenden, vorzugsweise nervösen Krankheiten. Franz Deuticke, Leipzig und Wien 1896.

2. v. Bechterew, Ueber die Kerne der mit den Augenbewegungen in Beziehung stehenden Nerven etc. Arch. f. Anat. u. Phys. 1897. Anat. Abth. Heft V u. VI.

3. Moeli, Weitere Mittheilungen über die Pupillenreaction. Ber]. klin. Woch. 1897. Nr. 18 u. 19. S. 373.

4. B ach, Ueber Augenmuskellähmungen. IV. Jahresversammlung der ophthalm. Gesellsch. Heidelberg, August 1897, Sitzung den 6. August. Vereinsbeil. der Deut. med. Woch. 1897. S. 163.

Derselbe, Ueber dieLocalisation der Oculomotoriuskerne. Versamml.d.Naturforscher und Aerzte in Frankfurt a. M. Neurol. Centralbl. 1896. S. 997.

5. Bernheimer, Experimentelle Studien zur Kenntniss der Innervation der inneren und äusseren, vom Oculomotorius versorgten Muskeln des Auges. Ein Beitrag zur Kenutniss der Beziehungen zwischen dem Ganglion ciliare und der Pupillenreaction. Separatabdruck aus v. Graefe's Arch. f. Ophthalm. XLIV. 1897.

Derselbe, Sitzung der Wiener Gesellsch. der Aerzte. Sitzung 26. März 1897. Wiener klin. Woch. 1897. S. 393.

6. Schwalbe, Lehrbuch der Neurologie. 1881.

7. Retziu s, Untersuchungen über die Nervenzellen der cerebrospinalen Ganglien und der übrigen periph. Kopfganglien. Arch. f. Anat. u. Physiol. Anat. Abth. 116. S. 369. 1880. (Jahresb. über Leist. u. Forsch. u. s. w. VirchowHirsch 1880. Bd. 1. S. 40.)

8. Kölliker, Handbuch der Gewebelehre des Menschen. 1896. II. Bd. II. Hälfte.

9. Apolant, Ueber das Ganglion ciliare. Physiol. Gesellsch. in Berlin. Sitzung am 24. Jan. 1895. Vereinsbeil. der Deut. med. Wochenschr. 1896. S. 31.

10. Chiarugi, Contribuzioni allo studio dello sviluppo dei nervi encefalici nei mammiferi in confronto con altri vertebrati. Sviluppo dei nervi oculomotori e trigemello. Publicazione del R. Instituto di studi in Firenze 1897. Riv. di patol. nerv. e mentale 1898. No. 1. p. 55.

11. Holtzmann, Untersuchungen über Ciliarganglien und Ciliarnerven. Morphol. Arbeiten. VI. Bd. I. Heft. 1896.

12. Antonelli, Contributo allo studio del significato morfologico e della struttura del ganglio ciliare. Giornale della associazione dei naturalisti e medici di Napoli. Anno I, puntata 3.

13. D'Erchia, Contributo allo studio della struttura e delle connessioni del ganglio ciliare. Monitore zoologico italiano. Anno V. Fasc. 9-10. $1894 \mathrm{ed.}$ anno VI. Fase. 7. 1895.

14. Marina, Eine Fixationsmethode, bei welcher'sowohl die Nissl'sche Nervenzelle, als die W eiger t'sche Markscheidenfärbung gelingt. Neurol. Centralbl. 1897. Nr. 4. (Rivista die patol. nerv, e mentale. Vol. II, fasc. 1. 1897.)

15. Hahn, Untersuchungen über den histologischen Bau der Ciliarnerven. Wien. klin. Wochenschr. 1897. Nr. 30. S. 714.

16. Marinesco, Recherches sur l'histologie des cellules du système sympathique. Revue neurologique 1898. No. 8. p. 230. 
17. Lngaro, Sulle alterazioni delle cellule nervose nella ipertermia sperimentale. Rivista di patologia nervosa e mentale 1898. Fasc. 5. p. 193.

18. Nissl, Studien zur Anatomie uno Histologie der Nervenzellen. Allgem. Zeitschr. f. Psych. etc. Bd. 54. Heft I u. II. 1897.

19. Derselbe, Nervenzelle und graue Substanz. Münch. med. Woch. 1898. Nr. 33. S. 1001.

20. F. Bottazzi, La fisiologia del simpatico secondo le ricerche di J. N. Langley e dei susi collaboratori. Rivista di patol. nerv. e mentale. Vol. III. Fasc. IV. p. 146. 1898.

21. Langley, Note on Regeneration of prae-ganglionic fibres of the symp. Journ. of Physiol. 18. 3. p. 280 (Neurol. Centralbl. 1895. S. 908).

22. Pándi. Ueber die Veränderungen des Centralnervensystems nach chronischer Vergiftung mit Brom, Cocain, Nicotin und Antipyrin. Separatabdr. aus dem Ung. Arch. f. Medicin. II. Bd.

23. 1. Coutarde et J. F. Guyon, Fonction réflexe du ganglion mésenterique inferieur. Compt. rend. de la Soc. de Biol. No. 27. 1897. (Riv. di patol. nerv. e ment. 1897. No. 8. p. 373.)

24. E. Jendrássik, Allgemeine Betrachtungen über das Wesen und die Functionen des vegetativen Nervensystems. Separatabdr. aus Virchow's Arch. 145. Bd. 1896 .

25. Jegorow, Récherches anatomo-physiol. sur le ganglion ophthalmique. Arch. sclares de biologie. Tome III. 1886 et Tome II. 1887 (citirt von An tonelli).

26. van Gehuchten, Anatomie du système nerveux de l'homme. Louvain 1897. p. $550-551$.

27. Paul Schultz, Ueber die Wirkungsweise der Mydriatica und Miotica. Arch. f. Anat. u. Psys. Physiol. Abth. 1898. I. u. II. Heft. S. 47.

28. Benda, Discussion: Ueber die Innervation des Herzens. Verein für innere Medicin in Berlin. Sitzung vom 27. Juni 1898. Münchn. med. Wochenschr. 1898. Nr. 28. S. 906.

29. Paul Schultz, Zur Physiologie der sympathischen Ganglien. Arch. f. Anat. u. Physiol. Physiol. Abth. 1898. I. u. II. Heft. S. 124.

\section{Erklärung der Abbildungen anf Tafel XIII.}

Fig. $1-3$.

Fig. 1. Affe B. Kauterisation der Cornea rechts. Rechtes Ganglion ciliare. Fix. Marina. Thionin. Oc. 4 comp. Object. D Zeiss. (Das Präparat wurde bei einer mässigen Vergrösserung gezeichnet, um ein grösseres Gesichtsfeld zu erreichen.)

Fig. 2. Affe G. II. Irideremie rechts. Rechtes G. ciliare. Fix. in 96 proc. Alkoh. Thionin. Oc. 4 comp. Object. E Zeiss.

Fig. 3. Affe F. Neurect. opticocil. rechts. Rechtes G. ciliare. Fix. Marina. Thionin. Oeul. 4 comp. Object. E Zeiss. 
Fig.1.

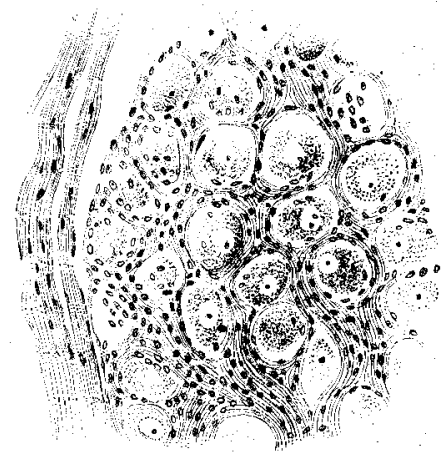

Fig.2.

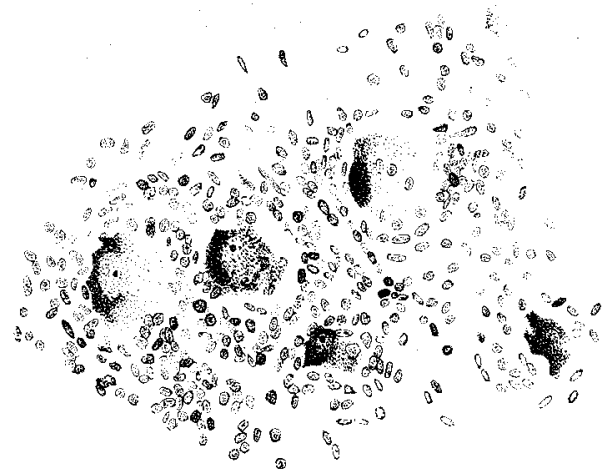

Fig. 3.

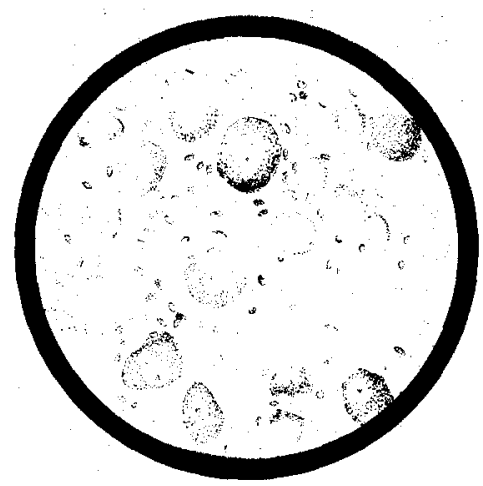

